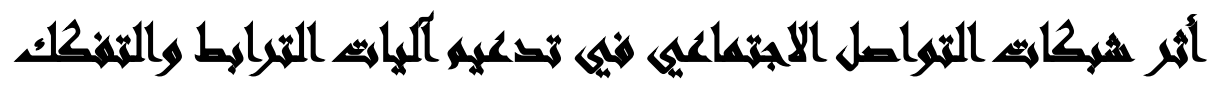

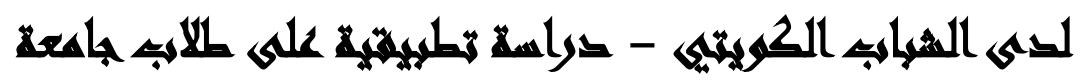 \\ 2لإll
}

[9]

فاطمة يوسف القليني(')- مرفت جمال الدين شمروخ(؟)-- عبد العزيز حمود الريحاني(ז)

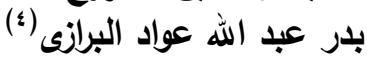

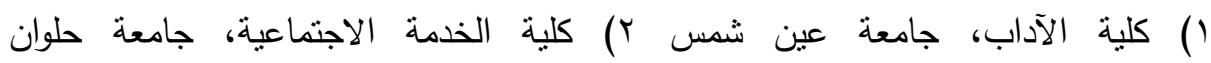
r) قسم الإعلام، جامعة الكويت ع ) القوات المسلحة الكويتية

\section{المستخلصى}

تتنمي هذه الدراسة إلى نمط الدراسات ؤالوصفية التحليلية لكونها أنسب أنواع الدراسات

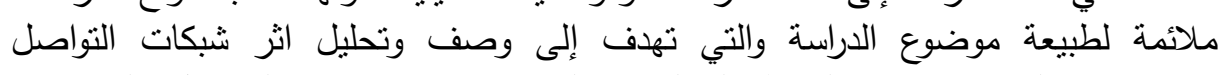

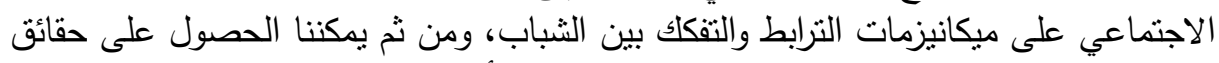

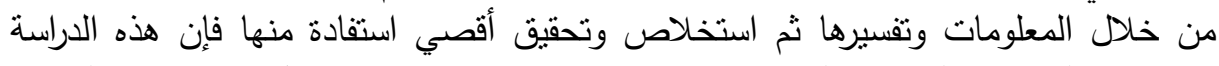

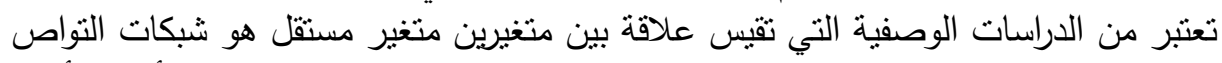

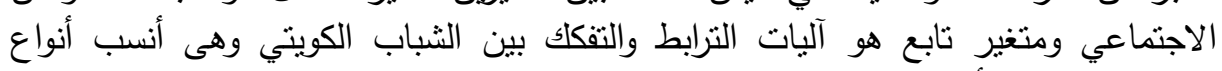

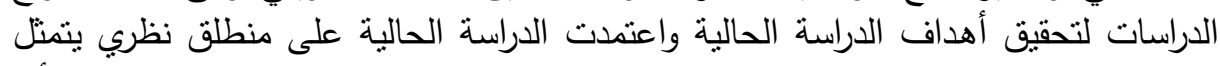

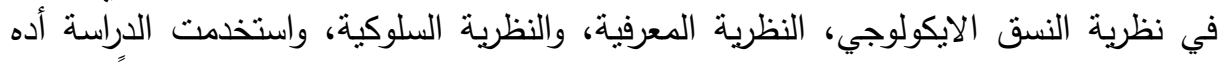

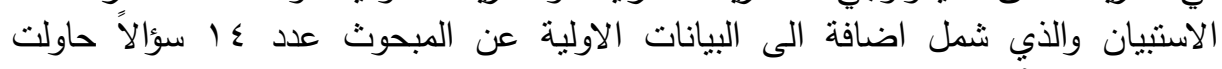

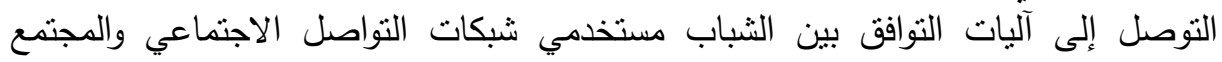

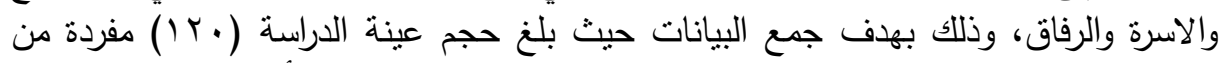

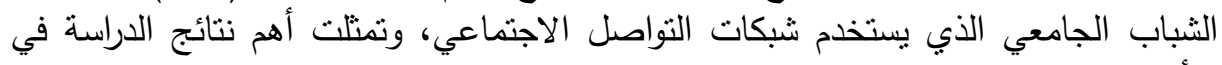

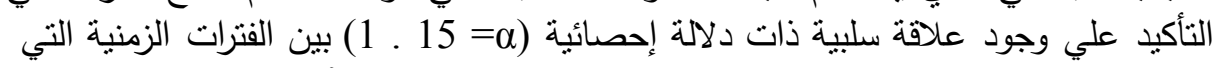

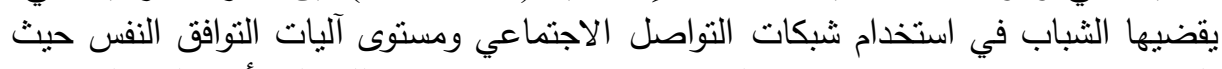

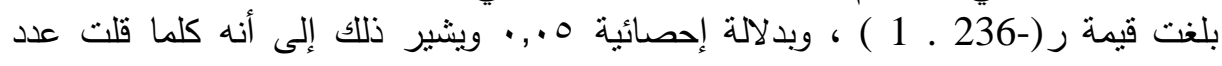

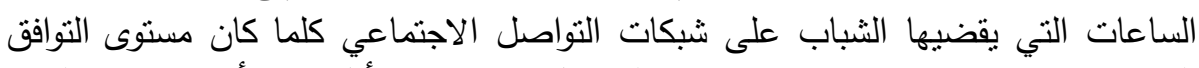

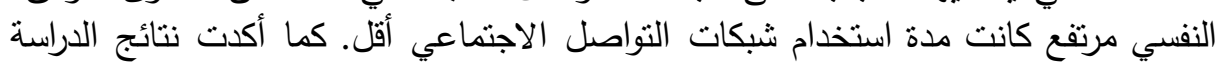

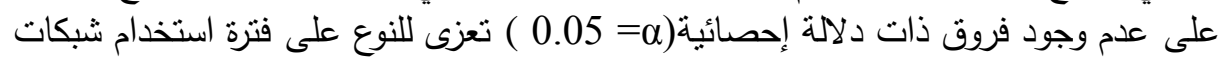

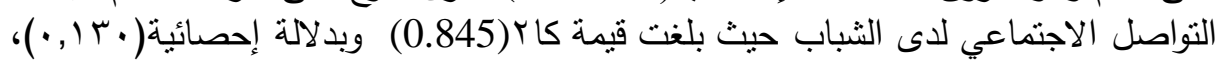

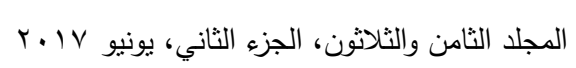


كما أكدت نتائج الدراسة على أنه توجد فروق دالة إحصائباً عند مستوى معنوية (0. , •) بين

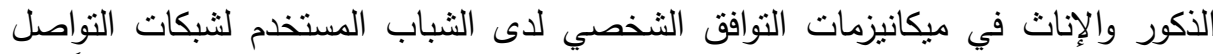

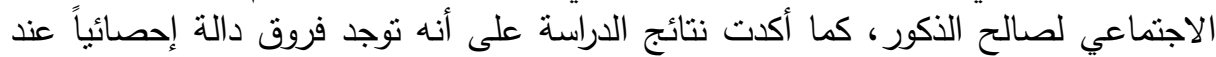

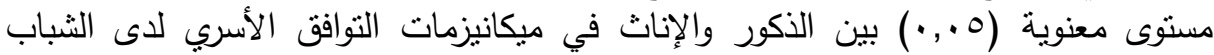

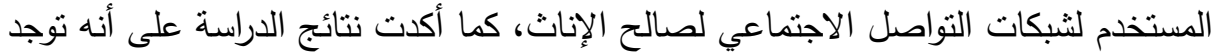

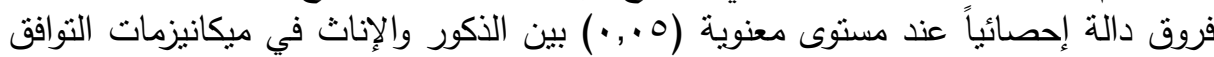

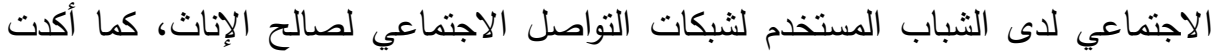

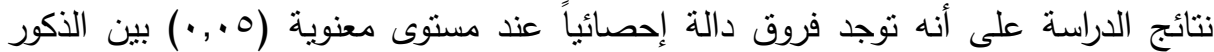

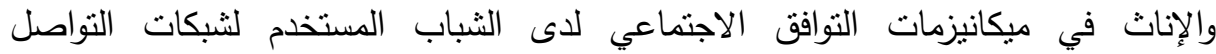

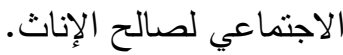
وأوصت الأدراسة بضرورة التعريف أكثر بأهمية الثبكات الاجنماعية، وذللك عن طريق عقد اللقاءات والمؤتمرات لذللك. وأوصت الدراسة ضرورة مخاطبة كليات الإعلام والمراكز البحثية المنتشرة على مستوى الوطن

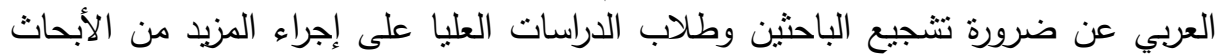
والدراسات عن مختلف شبكات التواصل الاجتماعي وتأثثراتها المختلفة على الفرد والمجتمع.

\section{$\operatorname{xan}$}

لقد شهدت عقود الثمانينيات والتسعينيات من القرن العشرين تركيزا ملحوظا على موضوع (المعرفة)، وعلاقتها بثورة التكنولوجيا والاتصالات من ناحية وعلاقتها بتتامي المجتمع

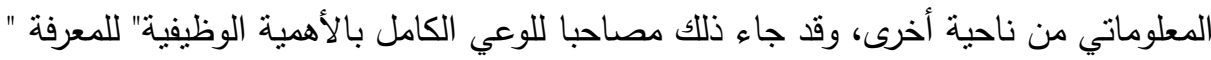

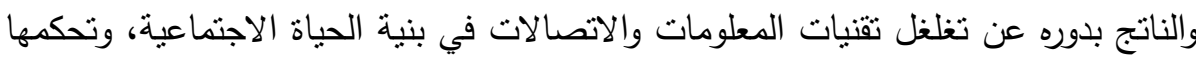
بشكل عضوي في شبكة العلاقات الاجتماعية للإنسان المعاصر، مما ساعد على ظهور

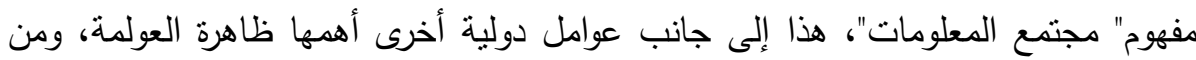
أجل تسهيل فهم القصد من العولمة التي حملت لنا معها مفهوم المجتمع المعلوماتي إن جاز

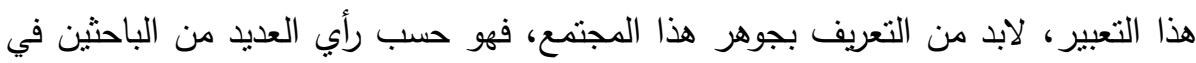
شُؤون الإعلام والاتصال" هو المجتمع الذي تتاح فيه لكل فرد فرصة الحصول على معلومات موثقة من أي شكل ولون ومذهب واتجاه ومن أي دولة من دول العالم دون استثناء، عبر

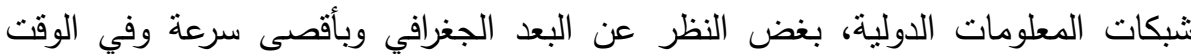


المناسب للمشاركة في عملية التبادل الإعلامي"، وهو أيضاً " المجتمع الذي تتحقق فيه إمكانية

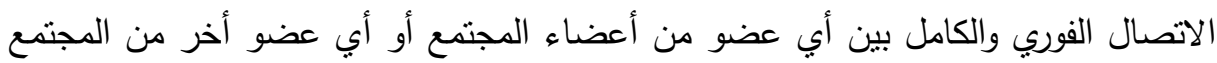

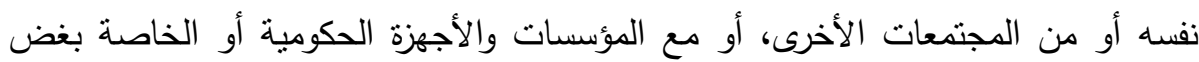

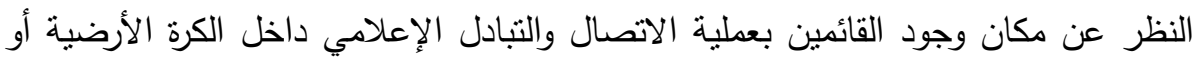

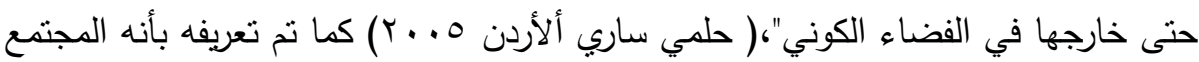

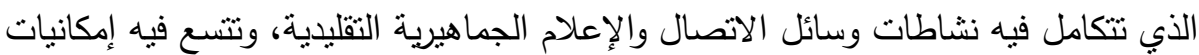

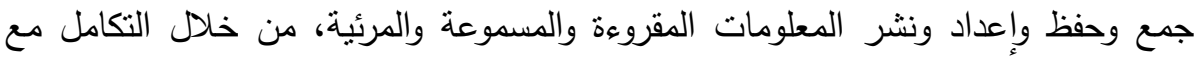

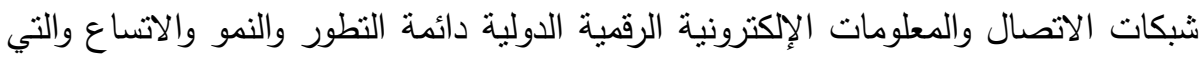
تتكل بالنتيجة وسط إعلامي مرئي ومسموع ينشر معلوماته عبر قنواته التي تتمل حتى وسائل الاتصال والإعلام الجماهيرية التقليدية من خلال شبكات الاتصال والمعلومات المحلية والإقليمية والدولية، وهو المجتمع الذي تختفي معه الحدود الجغرافية والسياسية للدول التي

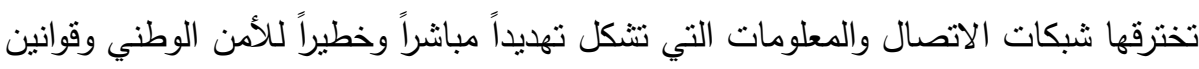
الدول وللأعراف والنقاليد داخل المجتمعات المختلفة، وخاصة في الدول الأقل حظا من التطور

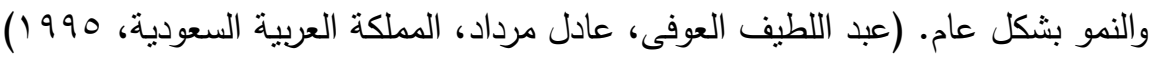

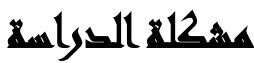

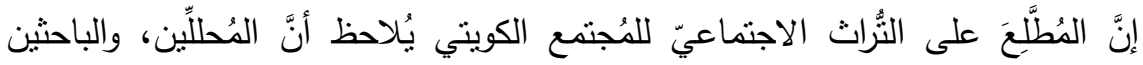

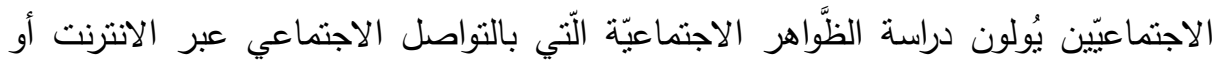

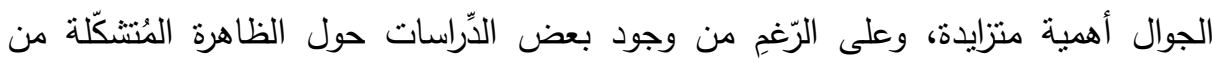

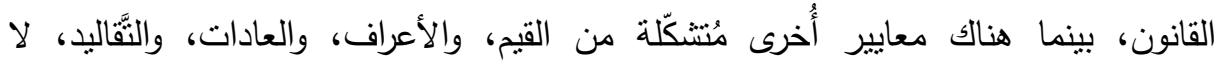
تستوجب مُخالفتها إيقاع عقوبات مُعيّنة من قِبل السلطة الحكومية القائمة، ـ ممّا يجعل الحاجة

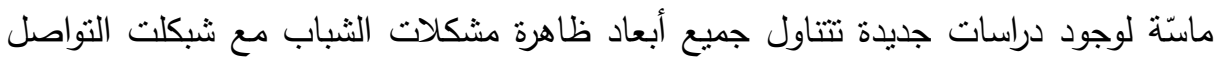
في المجتمع الكويتي. 
وقد وجد الباحثون أن معظم الدراسات التى تضع الحلول لمثل هذه المشكلة دراسات أجنبية أجريت فى بيئات تختلف نقافياً عن البيئة الكوينية ونتيجة لندرة الدراسات العربية العبية فالدراسة الحالية سوف تسعى إلى تلافى هذا القصور فى الدراسات العربية.

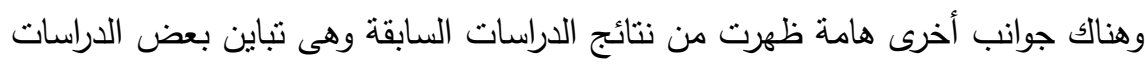

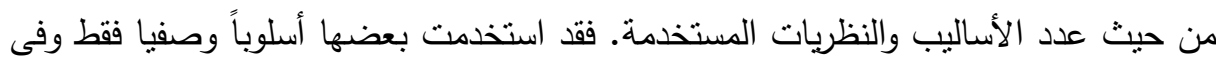
جانب آخر استخدمت بعض الدراسات الوصف والتحليل والمقارنه

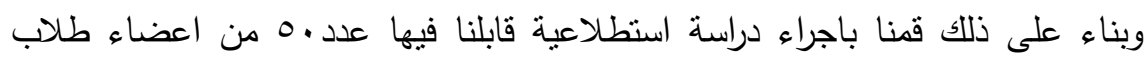

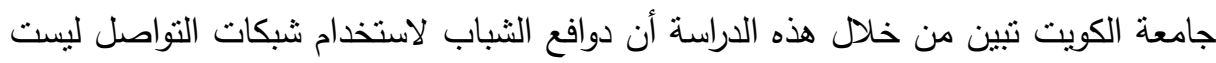

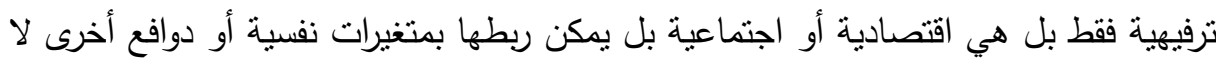

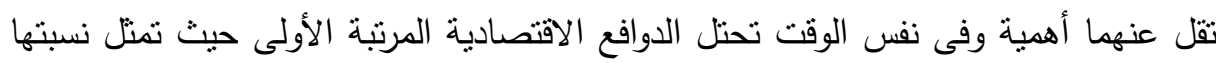

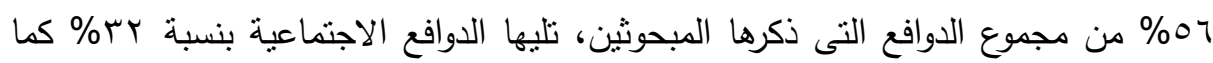

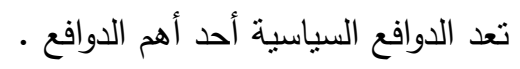
كل ذلك أوضح ضرورة وجود دراسات جديدة تنتاول الابعاد المختلفة لأثر شبكلت

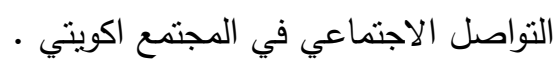
كما قام الباحث بتتاول المشكلة محل الدراسة مع المتخصصئ اكينين والدارسين والممارسين وكذا تتاول المتغيرات والجوانب المختلفة للمشكلة، أو النتائج والحلول المحتملة وإجراء دراسة مقارنة بالدراسات السابقة ومتغيرات جديدة، فقد أصبحت تقنيات الاتصال ونقل المعلومات رافداً أساسياً، وركناً مهاً في بناء منظومة الإنسان الاجتماعية، والاقتصادية، والسياسية، والثقافية،

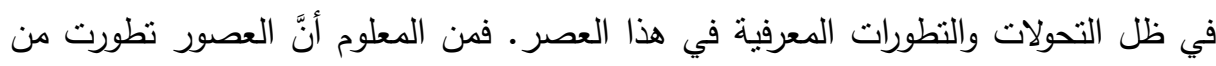

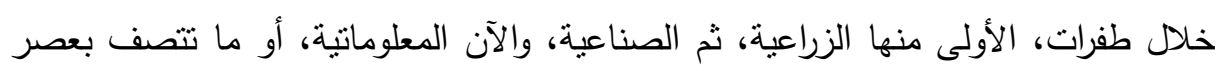

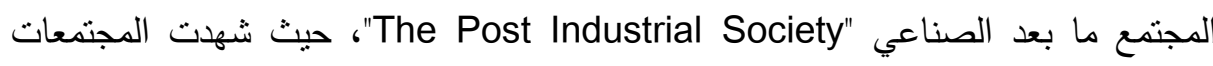
الإنسانية خلال العقد الأخير من القرن الماضي، نطورات منسارعة ومتلاحقة لتكنولوجيا

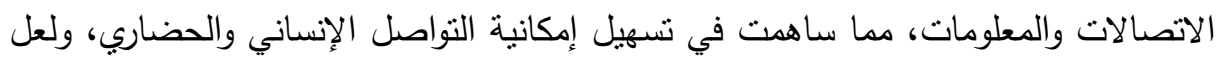


أهمها يتمنل في شبكة المعلومات العالمية "الإنترنت" التي تُعدُ أبرز ما توصل إليه العلم الحديث، ويعد كذلك من أهم الإنجازات البشرية في عصر المعلوماتية لهنية.

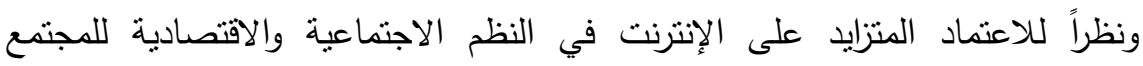

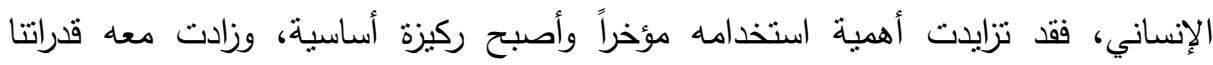
المعلوماتية والتفاعلية، ويصاحب ذللك أن العلاقات غير ثابتة ومن الصعب التبانية التتبؤ في تحديد

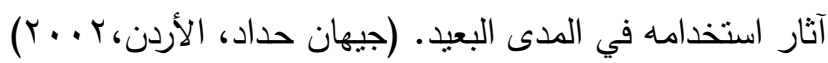

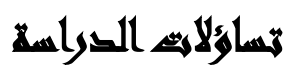

تعرف التساؤلات على أنها "التكهنات التي يضعها الباحثون لمعرفة الصلات بين النتائج والأسباب، أو أنها قضايا تصورية تحاول أن تفسر العلاقة بين اثثين أو أكثر من المتغيرات والأفكار". (فوضيل دليو ، الجزائر ، 999 (1) ) وقاء جاءت التساويلات كالتالي : ا ـ ما أثز شبكات التواصل الاجتماعي فى تدعيم أليات التواصل الاجتماعي؟

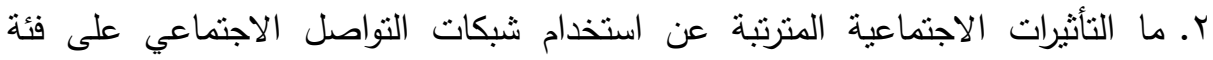
الشباب الجامعي؟

r. ما الخصائص العامة لسلوك مستخدمي الإنترنت، وتأثثراته على علاقاتهم الاجتماعية؟

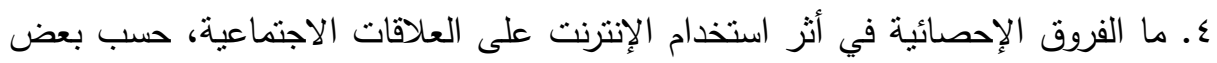
الخصائص النوعية لإقراد عينة الدراسة.

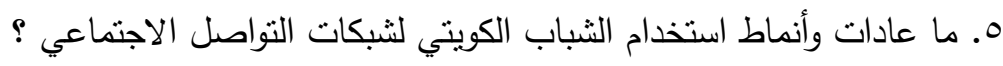

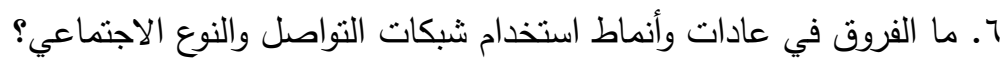

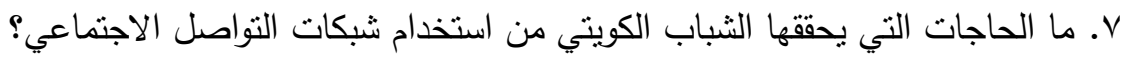
^. ما الفروق في الحاجات التي يحققها الثباب الكويتي من استخدام شبكات التواصل الاجتماعي تبعا لمتغيري النوع الاجتماعي ومدى الاستخدام؟ 


\section{أهساهنم الصوراسة}

ا. إفساح المجال لاهتمام متزايد بموضوع استخدام الإنترنت، ودراسة آثاره المختلفة على المجتمع، من خلال طرح هذا الموضوع أمام الباحثين ومتخذي القرار للسياسات الاجتماعية، حيث يؤمل أن يلقى مزيدا من الاهتمام والدراسات الميدانية في جوانب مختلفة

r. تحليل واقع ظاهرة استخدام الإنترنت، من حيث إبراز التأثنرات الاجتماعية المترتبة عن

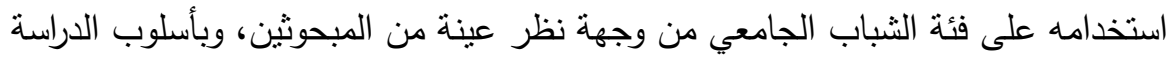

الميدانية.

r. الكثف عن أهم الخصائص العامة لسلوك مستخدمي الإنترنت، وتأثثراته على علاقاتهم

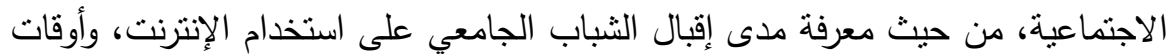

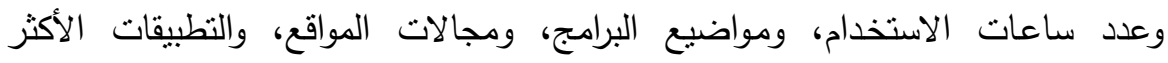
استخداماً له.

ع. التعرف على أهم الفروق الإحصائية في أثر استخدام الإنترنت على العلاقات الاجتماعية، حسب بعض الخصائص النوعية لإفراد عينة الدراسة. ه. الاستفادة من نتائج هذه الدراسة، وفتح الطريق أمام إجراء دراسات أخرى في بيئات مشابهه

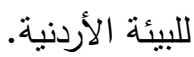

\section{أهمية التصواسم}

تظهر أهمية هذه الدراسة من خلال مساهمتها في إثراء الأدبيات السوسيولوجية والسيكولوجية حول ظاهرة استخدام الإنترنت كإحدى وسائل التكنولوجيا الحديثة، حيث تزايدت إعداد مستخدميه في الآونة الأخيرة بشكل لافت للنظر ، واتسع نطاق نأثيراته المباشرة في ثقافة

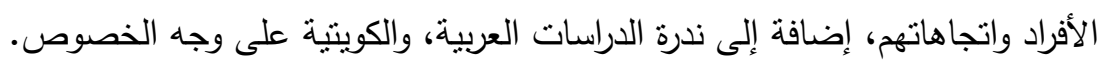
ا ـ تكمن أهمية هذا البحث في أنّه من البحوث التي تتعنى بموضوعات العصر وتنتامي دور الثباب في رسم خريطة التغيير السياسي في الوطن العربي. 
r. تتناول هذه الدراسة ظاهرة هامة من ظواهر العصر الحديث وهي مواقع التواصل الاجتماعي.

r. نسلط الضوء على العلاقة بين مواقع التواصل الاجتماعي ومهارات التواصل الاجتماعي.

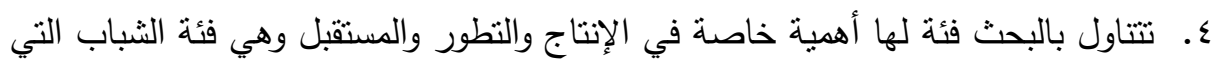
يجب إعدادها لمواجهة الثورة العلمية المعرفية. ه. إفساح المجال لاهتمام متزايد بموضوع استخدام شبكات التواصل الاجتماعي، ودراسة آثاره المختلفة على المجتمع، من خلال طرح هذا الموضوع أمام الباحثين ومتخذي القرار

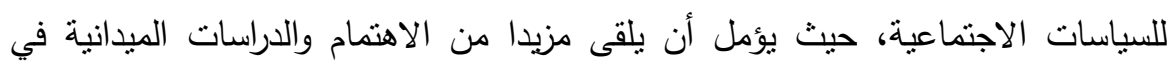
جوانب مختلفة منه. 7. تحليل واقع ظاهرة استخدام شبكات التواصل الاجتماعي، من حيث إبراز التأثيرات

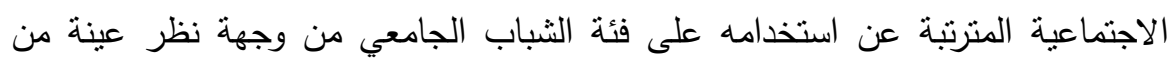
المبحوثين، وبأسلوب الدراسة الميدانية. V. الكثف عن أهم الخصائص العامة لسلوك مستخدمي شبكات التواصل الاجتماعي،

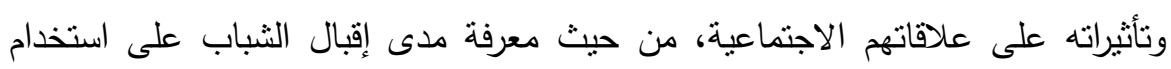

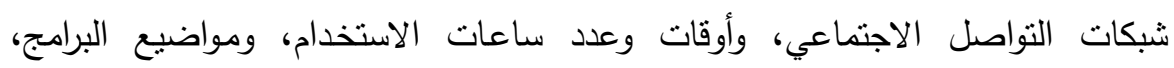
ومجالات المواقع، والتطبيقات الأكثز استخداماً له. ^. الاستفادة من نتائج هذه الدراسة، وفتح الطريق أمام إجراء دراسات أخرى في نفس الهجات الهال.

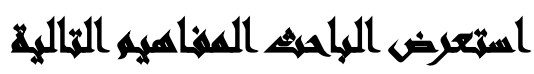

مفهوم التواصل الاجتماعي: يعد مفهوم " مواقع التواصل الاجتماعي" من المفاهيم المثير للجدل، نظرا لتداخل الآراء والاتجاهات في دراسته. حيث عكَ هذا المفهوم، التهوم التطور التقني الذي طرأ على استخدام التكنولوجيا، وأُطلق على كل ما يمكن استخدامه من قبل الأله الأفراد والجماعات على الثبكة العنكبوتية العملاقة. 
حيث يعرف بأنه " بالمحتوى الذي يتميز بالطابع الثخصي، والمتناقَل بين طرفين أحدهما

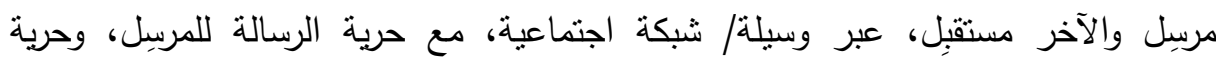
التجاوب معها للمستقبل".

ويعرف أيضاً بأنه " الطرق الجديدة في الاتصال في البيئة الرقمية بما يسمح للمجموعات

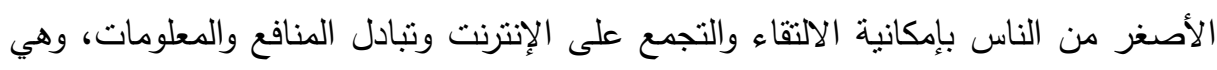
بيئة تسمح للإفراد والمجموعات بإسماع صوتهم وصوت مجتمعاتهم إلى العالم اجمع".( زاهر

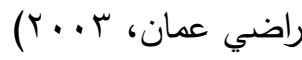
كما تعرف أيضاً بأنها "منظومة من الثبكات الإككترونيّة التي تسمح للمشترك فيها بإنثاء

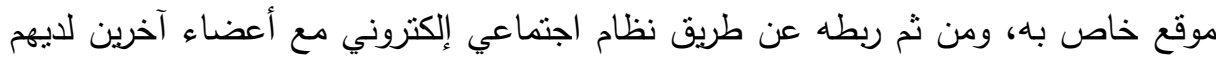

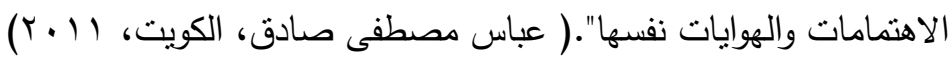
كما تعرف أيضاً " نوع من التواصل الذي يقدم في شكل رقمي وتفاعلي، ويعتمد على اندماج النص والصورة والفيديو والصوت، فضلا عن استخدام الكومبيوتر كآلية رئيسة له في عملية الانتاج والعرض، اما التفاعلية فهي تمثل الفارق الرئيس الذي يميزه وهي اهم سماته. ( عباس التهن

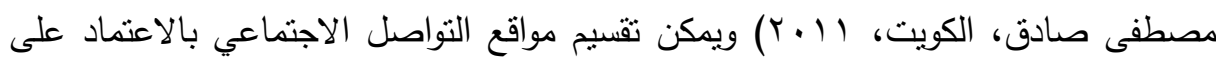

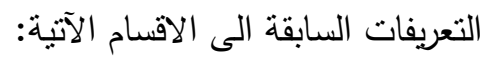
1 شبكة الانترنت Online وتطبيقاتها، منل الفيس بوك، وتويتر، اليوتيوب، والمدونات،

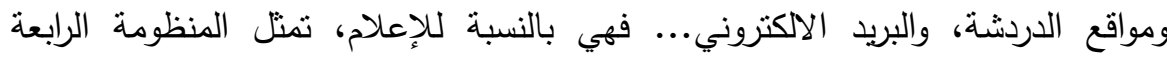
تضاف للمنظومات الكلاسيكية الثلاث. r- تطبيقات قائمة على الأدوات المحمولة المختلفة ومنها أجهزة الهاتف الذكية والمساعدات الرقمية الثخصية وغيرها. وتُعدّ الأجهزة المحمولة منظومة خامسة في طور التتكل.

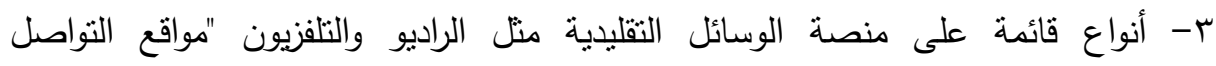
الاجتماعي للقنوات والإذاعات والبرامج " التي أضيفت إليها ميزات منل التفاعلية والرقمية والاستجابة للطلب. 
ويمكن ان نخلص إلى شبه اتفاق، أن مواقع التواصل الاجتماعي تشير إلى حالة من

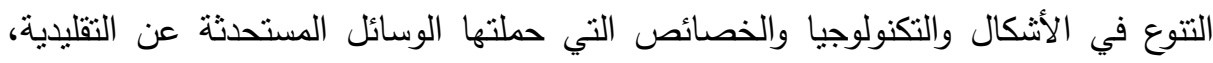
لاسيما فيما يتعلق بإعلاء حالات الفردية اوالتخصي وتأتيان نتيجة لميزة رئيسة هي التفاعلية مفهوم الانترنـت : هو تلك الثبكة الالكترونية المكونـة من مجموعة من الثبكات التي تربط النـاس والمعلومـات، مـن خـلال أجهزة الكمبيوتز والأجهزة الرقميـة، بحيث تسـح بالاتصـال بين

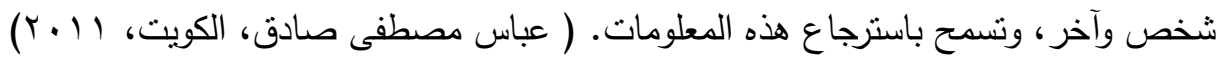
مفهوم آليـات التفكـك: إذا كانت بعض الدوافع في الإنسـان تتنمي إلى القوة الروحيـة بينما

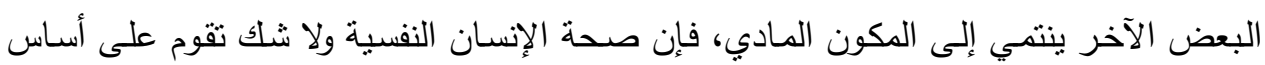
وصول الإنسان إلى حالة التوازن والاعتدال في الإثباع بين حاجات ودوافع هاتين القوتين.

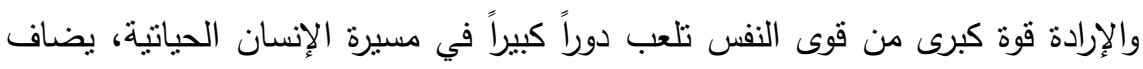

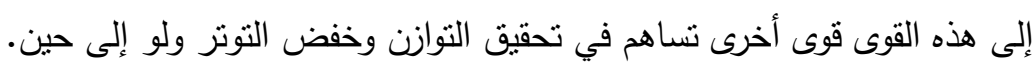
وقد تتاول علماء النفس بعض هذه القوى فيما سمى بميكانزمات الدفاع أو الحيل العقلية،

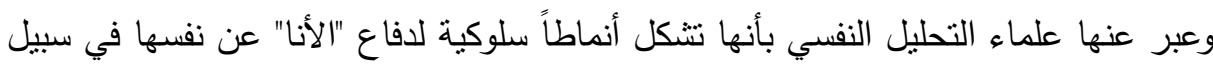
إعادة التوازن للشخصية، حين يختل هذا التوازن الذي يمكن أن يصل بالإنسان إلى الإحباط والقلق والصراع أو اضطرابات نفسية وعقلية أكثر أثراً.

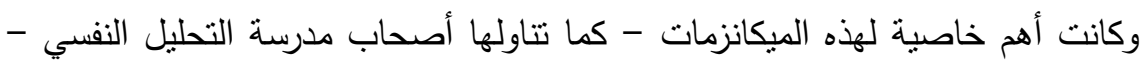

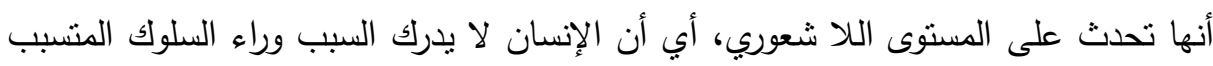

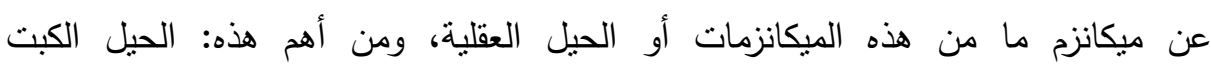
Repression Rrojection .Sublimation 


\section{التراسايت الماريها}

دراسة تحسين منصور(ى . r م): "استخدام الإنترنت ودوافعها لاى طلة جامعة

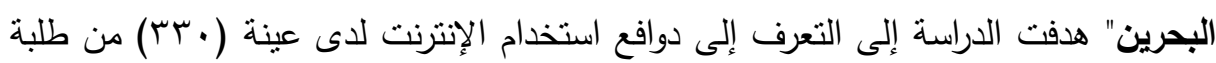

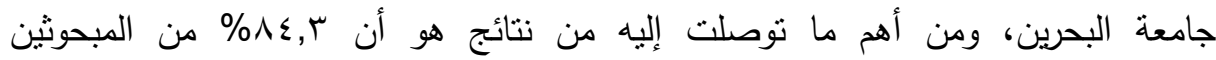
يستخدمون خدمة البريد الالكتروني في المرنبة الأولى، وعدم وجود فروق ذات دلالة إحصائية

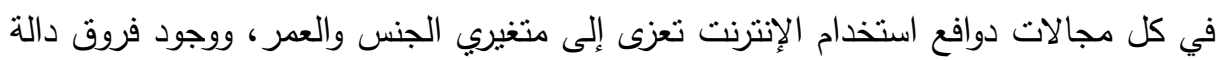

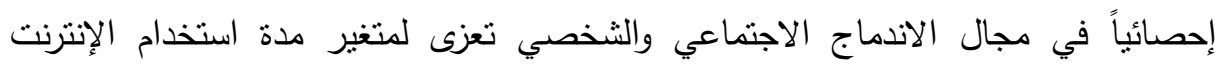

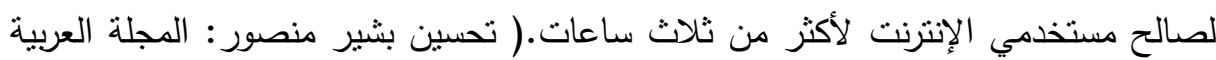

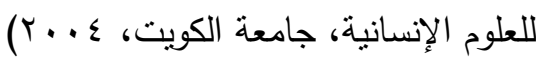

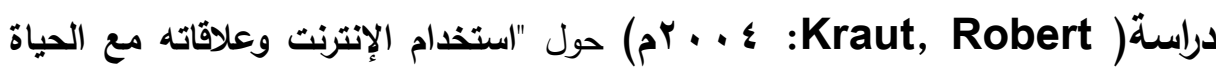
الاجتماعية والنفسية"، وأثارت نتائجها إلى أن هناك دلائل يمكن الاعنماد عليها ضمن

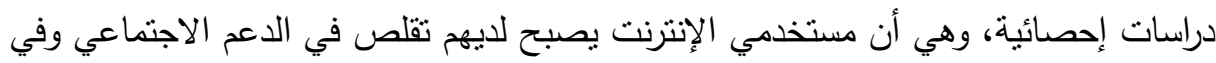

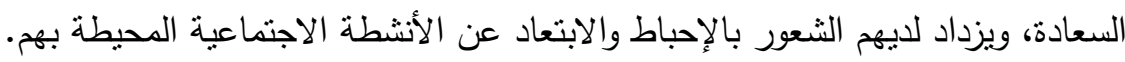

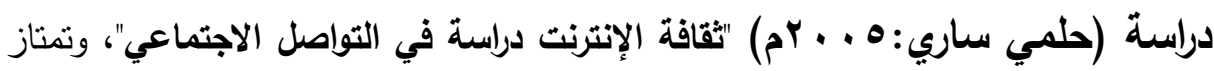
هذه الدراسة بشموليتها وتوسعها في المجال المعرفي، بما يخص تكنولوجيا المعلومات، سواء

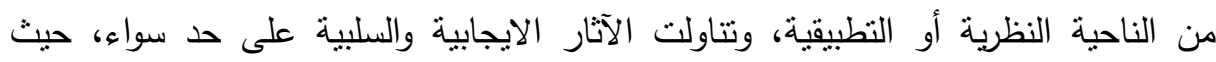

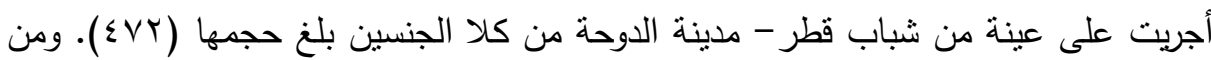

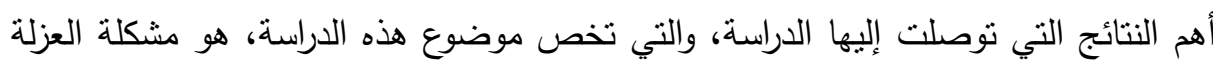
النفسية والاجتماعية الناجمة عن الإدمان على استخدام شبكة الإنترنت، ومن أهم أعراضها:

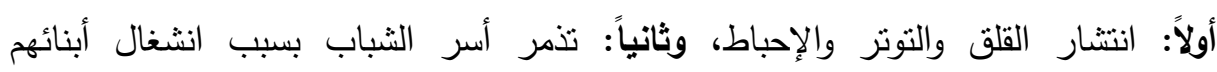

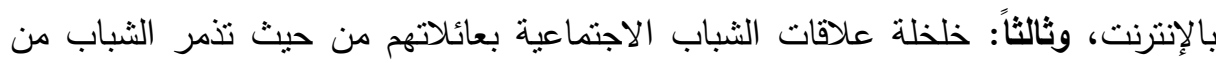

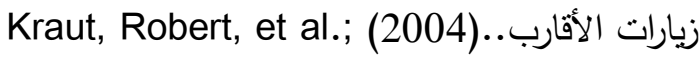




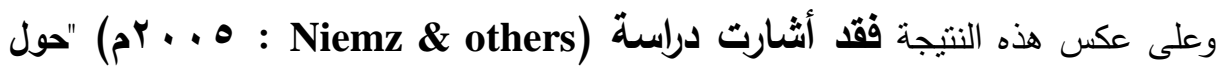
الاستخدام المرضي للانترنت لاى طلبة الجامعة وارتباطه باحترام الأات"، حيث أثنارت نتائجها إلى أن طلبة الجامعة يستخدمون الإنترنت في كثير من المواقف من اجل الدعم الاجتماعي، وليس من اجل استبداله. وحول انعكاس استخدام الإنترنت على المشاركة

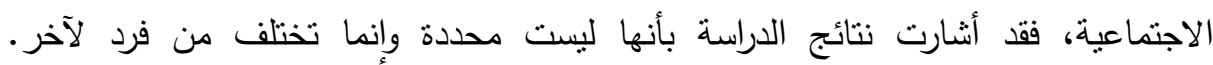
(Niemz,) Katie, Mark Griffiths and Phil Banyrad كما تتاولت دراسة (Aren karbnsky 2010)التعرف على أثز استخدام موقع " فيس بوك " على التحصيل الدراسي لدى طلبة الجامعات، وقد طبقت الدراسة على"219" طالباً

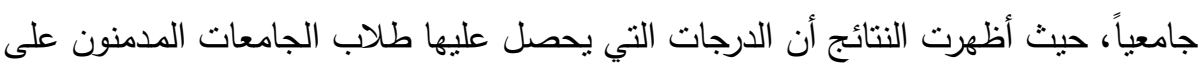
شبكة الانترنت وتصفح موقع " فيس بوك " أكبر الثبكات الاجتماعية على الإنترنت أدنى بكثير من تلك التي يحصل عليها نظراؤهم الذين لا يستخدمون هذا الموقع، كما أظهرت النتائج النه

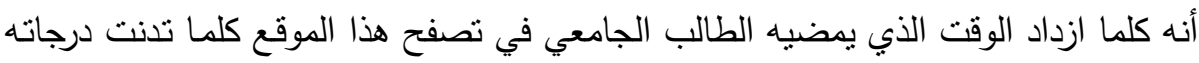

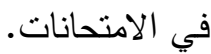
كما بينت النتائج أن الأشخاص الذين يقضون وقتاً أطول على الانترنت يخصصون وقتاً

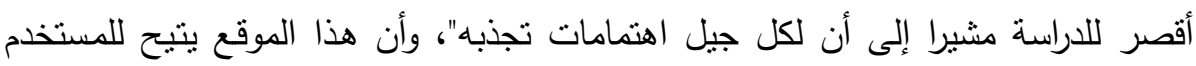

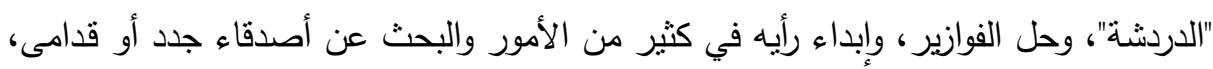
وبينت النتائج إن 79 \% من الطلاب الجامعيين الذين شملتهم الدراسة اعترفوا بأن إدمانهم على موقع " الفيس بوك " أثزّ سلبياً على تحصيلهم الدراسي.(Aren, Karbiniski K2004 ) ويالنسبة للإطار النظرى للاراسة استعان الباحثون بنظرية النسق الإيكولوجي الذي يعد من

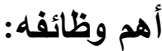
1- الوظيفة الأولي: هي وظيفة داخلية وتتمنل في الحفاظ على العلاقات المتوازنة بين الأجزاء المكونة للنسق. r- الوظيفة الثانية: هي وظيفة خارجية وتتمثل في التفاعل مع البيئة وأداء الوظيفة المطلوبة من النسق الإيكولوجي، يعني أن النسق يحتوى علي عناصر بعضها بعمل من أجل الحفاظ

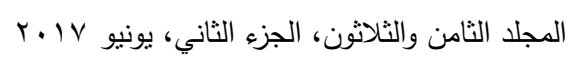


علي الوضع القائم بينما هناك عناصر أخري تتحرك نحو التغير • (فاروق ذكى يونس، جامعة حلوان، 99 ( )

إن النسق الإيكولوجي في حالة حركة مستمرة وتغير دائم سواء من داخل الأنساق الفرعية

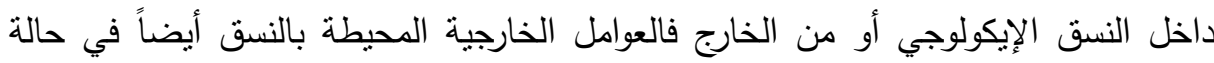

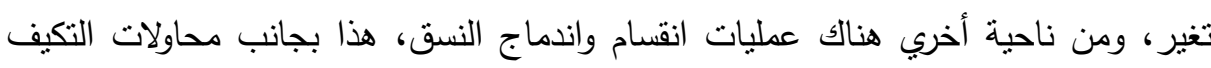

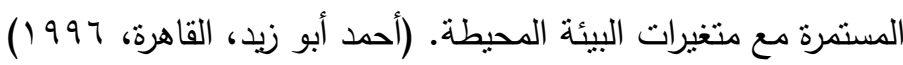
والنسق الإيكولوجي له بناء وعناصر حية وغير حية وذلك في إطار بناء تفاعلي متكامل، وهو في نفس الوقت نسق وظيفي بمعني أن العمليات التفاعلية تتم في ضوء الإكوريه والدوار الوظيفية التي تلعبها مقومات النسق الأساسية من أجل استمراره وبقائه. (السيد عبد العاطي

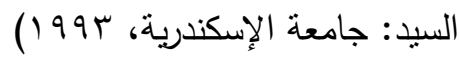
يختلف العلماء حول استقلالية النسق الإيكولوجي وهل هو نسق قائم بذاته ومنفصل أم

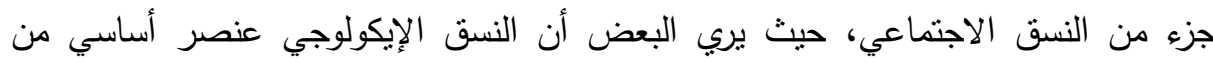

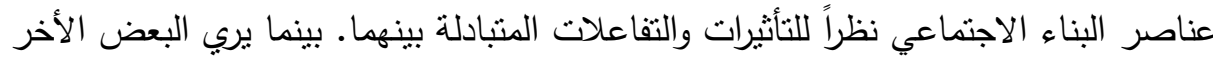

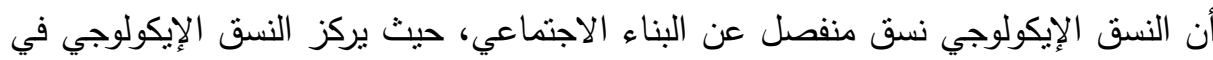
المقام الأول على دراسة العلاقة بين الإنسان والطبيعة. (أحمد أبو زيد، الإسكندرية، 9 . . ب)

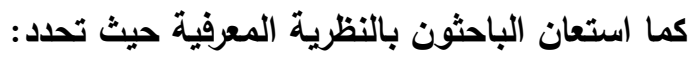
1- أن النشاط المعرفي يؤثر في السلوك. r- أن النشاط المعرفي يمكن قياسه واختباره وتغييره. r- أنه من المككن استبدال السلوك السلبي عن طريق تغيير الأفكار الخاطئة.

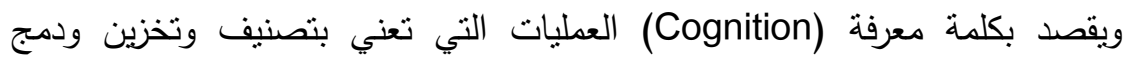
المعلومات التي يتعرض لها الإنسان مع المعارف الموجودة لديه، واستدعاء واستخدام هذه لهاه

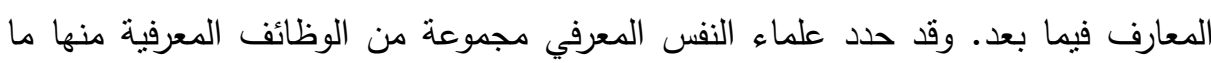

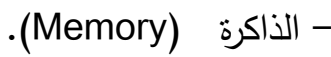
- (Attention) الانتباه - 


$$
\begin{aligned}
& \text { - الإدراك (Perception) - }
\end{aligned}
$$

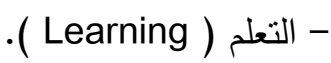

$$
\begin{aligned}
& \text { - التفكير (Thinking). } \\
& \text { - الحكم على الأمور (Judgment) - } \\
& \text { - تكوين المفاهيم( Conception). } \\
& \text { - اتخاذ القرار (Decision making ). }
\end{aligned}
$$

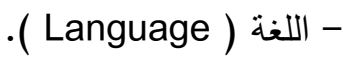

$$
\begin{aligned}
& \text { - التخطيط(Planning). - حل المشكلات(Problem solving). }
\end{aligned}
$$

فالعلاج المعرفي أحد طرق العلاج النفسي الذي يستخدم في الكثير من الأمراض

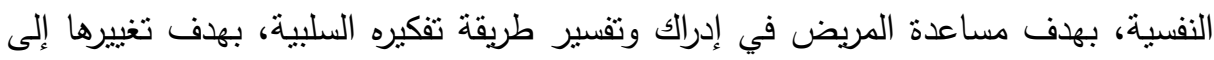

أفكار ايجابية أكثر واقعية، يمكن أن يستخدم. (Spiro, R, 1991)

ومن مسلمات النظرية المعرفية:

ا. المصادر الأساسية للأداء أو التكيف النفسي هي الأبنية المعرفية التي تقوم بتشكيل المعاني والتي تسمى المخطوطات المعرفية , Schema ويقصد بالمعنى تقسير الثخص الثص لسياق معين ، وعلاقة هذا السياق بالذات. r. مهمة عملية إعطاء المعاني هذه ( على المستوى التلقائي أو المقصود ) هي محاولة

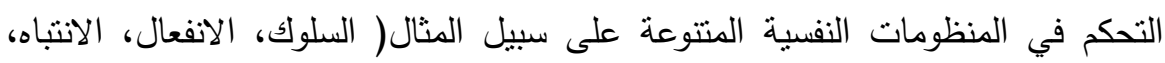
والتذكر)، وهكذا فإن المعنى ينشط الاستراتيجيات الخاصة بالتكيف. r. هناك تأثثر منبادل بين المنظومات المعرفية والمنظومات الأخرى.

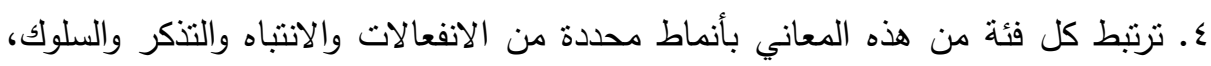

$$
\text { وتسمى هذه العمليات بخصوصية المحتوى المعرفي. }
$$

0. ومع أن المعاني من صنع الثخص، وليست بالضرورة أثنياء موجودة من قبل في الواقع فإنها تكون صائبة أو خاطئة من حيث علان منتها بسياق أو هدف معين. وعندما يحدث التشويه المعرفي أو التحيز تكون المعاني غير فعالة أو غير تكيفيه، ويشتمل التشويه المعرفي على أخطاء في المحتوى المعرفي(المعنى) أو في المعالجة المعرفية(تفسير المعاني)، أو في الاثثين معاً. (آمال صادق، وفؤاد أبو حطب، القاهرة، ، 99 (1) )

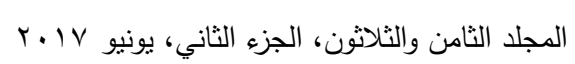


ويمكن النظر إلى النظرية المعرفية من منظورين وهما:

- المنظور الأول: التراكيب المعرفية (العقلية): أن التكيف العقلي أو المعرفي يقتضي مني وجود مجموعة من التراكيب المعرفية أو العقلية داخل عقل الإنسان وأن هذه التراكيب

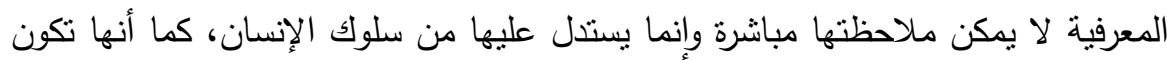

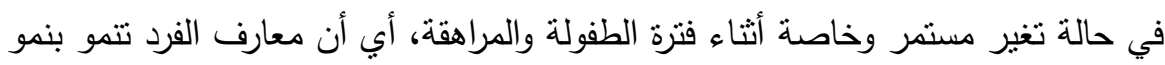
عقله أي بتطور ذهنه.

- المنظور الثاني: الوظائف العقلية: ويقصد بالوظائف العقلية بالعمليات التي يلجأ

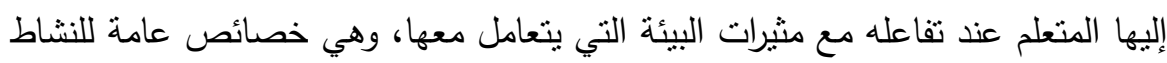
العقلي وتقتصر تلك الوظائف التي لا تتغير مع العمر علي : -

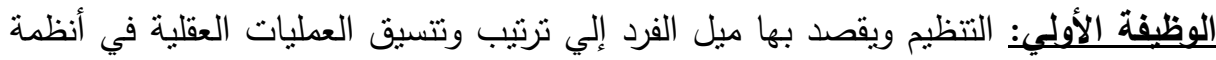
كلبة ومتتاسقة.

الوظيفة الثانية : التكيف ويقصد بها ميل الفرد إلي التآلف مع البيئة التي يعيش فيها.

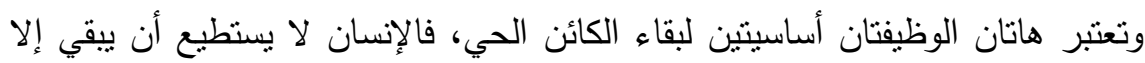

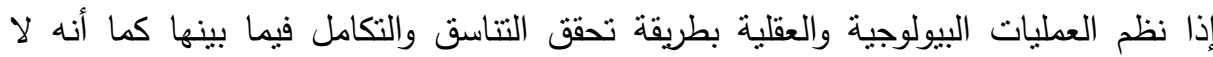
يسنطيع البقاء إذا لم يتمكن من التكيف مع البيئة التي يعيش فيها.

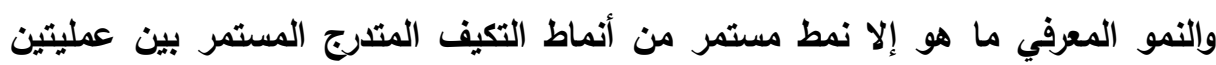
عقليتين متكاملتين هما: 1- التمثيل: ويقصد به ميل الفرد لدمج أمورا من العالم الخارجي في بنائه العقلي، أو نتظيم الخبرات الجديدة مع التكوينات الموجودة أصلاً. r- الاستيعاب: ويقصد به إعادة تتظيم البنية المعرفية للفرد لكي تتوافق مع متطلبات البيئة، أو هو ميل الفرد لتغيير استجابته ليتلاعم مع البيئة المحيطة به. ( Appleton , k, 
كما استعان الباحثون بالنظرية السلوكية: حيث فسرت النظرية السلوكية عملية التعلم من الناحية الكمية، وظهر ذلك بوضوح فيما نوصل إليه علماء النظرية السلوكية من قوانين ومبادئ لعمليتي التعليم والتعلم وفقاً للنظرية السلوكية. - ومن أهم القوانين التي نتجت عن تجارب النظرية السلوكية:- (إيراهيم وجيه محمود،

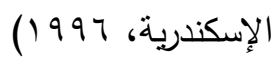

1 - قانون الأثر "law of effect": إن عامل السرور أو الارتياح الناتج عن الاستجابة يعمل

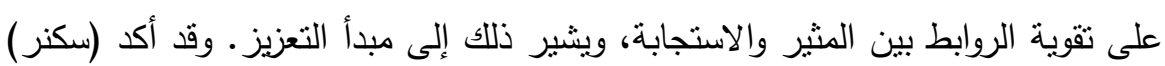
على أن التعزيز الذي يصاحب السلوك الذي يقوم به الفرد يقوى إجراء، كما إن مضى ثوان

$$
\text { بين الاستجابة وتعزيزها لا يؤدى إلى نتيجة. }
$$

ب- قانون التمرين"law of exercise": بشير إلى تقوية الروابط نتيجة التمرين (الاستعمال)، وأن التمرين يجب أن يكون موجهاً (تغذية راجعة)؛ ليكتشف المتعلم أخطاءه

ب- قانون الاستعداد "law of readiness": ويثير إلى أنه كلما كانت الوحدات العصبية التوصيلية مستعدة للتوصيل، أي لأداء سلوك ما، فسيكون هذا الأداء مريحاً ومرضياً.

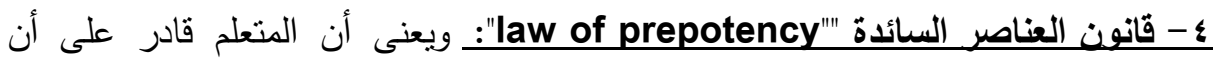
يستجيب للعناصر السائدة في المشكلة، أي يكون لديه القدرة على أن ينتقى العنصر المهر في المواقف، وأن يوجه استجاباته إليه. ه- قانون التجميع: يسهل على الارتباطات أن تسلك الاتجاه الذي تكونت فيه أو سلكته، إنهاته إنهانه

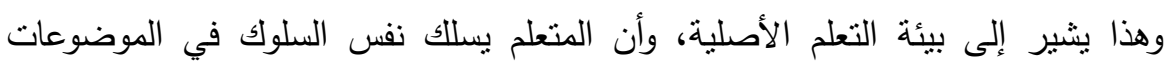

$$
\text { المشابهة. }
$$

צ- قانون البسر:_كلما كانت الاستجابة في تتاول الفرد وفى مقدرته أن يعملها، كلما كان أكثر سهولة في ارتباطها بموقف التعلم، ويهنم هذا القانون بعامل النضج. V- انتقال أثر التعلم.: ينتقل التعلم إلى المواقف الجديدة بسبب العناصر المشتركة بين الموقف القديم والموقف الجديد.

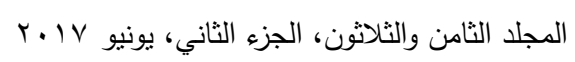


ويستتتج من هذه القوانين وغيرها من القوانين الأخرى مبادئ التصميم التعليمي من المنظور

1- وصف السلوك أو الأداء الذي يقوم به المتعلم، وتحديده، وتحليله، وتجزئته إلى عناصره

$$
\text { الفرعية. }
$$

r- الاهتمام بثقديم كل المعلومات والمثيرات لتحقيق السلوك المرغوب.

r- صباغة مثيرات بطريقة مندرجة من السهل إلى الصعب، بومن البسيط إلى المعقد.

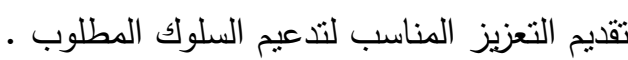
ع- الاهتمام بعمليات تكرار السلوك؛ لنقوية الربط بين المثيرات والاستجابات. 0- الاهتمام فقط بتأثير الخبرات الماضية في التعلم دون الحاضرة. צ- الاهتمام بالدافعية: خارجية أو داخلية، وإثباع الحاجة، للحصول على دلى الرضير الرضا، وتحقيق

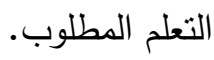

V- التعلم هو تغير في السلوك نتيجة للمعلومات التي يحصل عليها الفرد. ^- يتم تقويم التعلم على أساس أداء السلوك المحدد. (أنسى محمد أحمد قاسم، الإسكندرية،

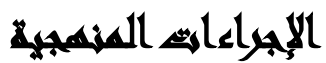

أولاً: مجالات الدراسة: تحددت مجالات الدراسة في المجال المكاني والمجال البشري والمجال الزمني وذللك على النحو التالي: المان

1- المجال المكاني: قام الباحثون باختيار المجال المكاني للاراسة بالتطبيق علي الثباب الجامعى بجامعة الكويت.

r- المجال البشري: تمثنل المجال البشري للاراسة الحالية على النحو التالي:-

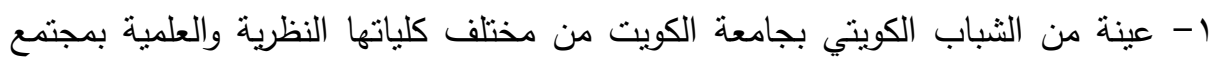
الدراسة عن طريق القانون الأمنل لتحديد حجم العينة العشوائية البسيطة بمجتمع الدراسة من لهنية

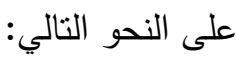


عند تقدير الحجم الأمتل للعينة، يمكن استخدام معادلات إحصائية تفيد ذلك، لأنه من غير

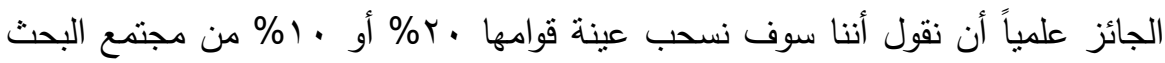

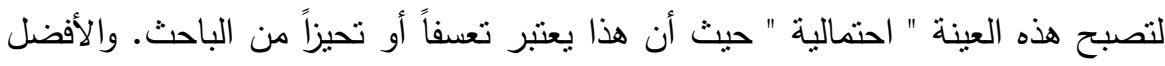
أن نتبع تقنيات عمل الإحصاء الذي يوفر معادلات لتحديد الحجم الأمتل للعينة وفقاً لدرجة الدأنة

$$
\text { ثقة عالية 90\% ( مستوى معنوية 0, •) }
$$

وفيما يلي جدول يوضح أطار المعاينة لعينة الدراسة من بناءات القوة في الريف والحضر . جدول(ץ): يوضح حجم إطار المعاينة للمجال البشرى لعينة الدراسة

\begin{tabular}{|c|c|c|c|}
\hline حجم العينة & حجم الطلاب بالجامعة & مجتمع الدراسة & P \\
\hline Ir. & $\varepsilon \wedge \Delta Y$ & جامعة الكويت & 1 \\
\hline
\end{tabular}

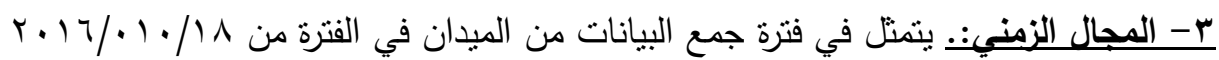

$$
\text { حنى }
$$

ثانياً: المنهج المستخدم في البحث: ونظرًا لطبيعة الموضوع المعالج، فقد نم توظيف يشير مفهوم المنهج إلى الطريقة التي ينبعها الباحث لدراسة المشكلة موضوع الدراسة. (عبد

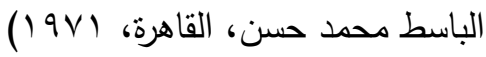

أو الطريقة التي يتبعها الباحث في دراسته للمشكلة لاكتشاف الحقيقة، وللإجابة على الأسئلة والاستفسارات التي يثيرها موضوع البحث وهو البرنامج الذي يحدد لنا السبيل للوصول

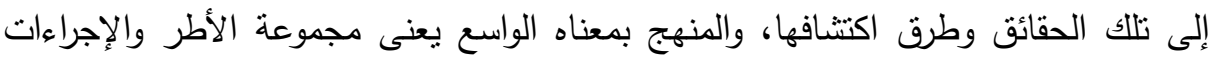

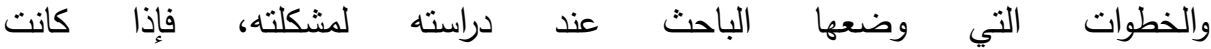
ستجرى على البشر فيسمى هذا بمنهج المسح الاجتماعي Social Survey. (محمد شفيق،

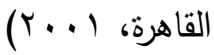
وتتنهج الدراسة الحالية منهج المسح الاجتماعي بالعينة ذلك أن منهج المسح الاجتماعي يهدف إلى الوصول إلى بيانات يمكن تصنيفها وتفسيرها وتعميمها وذلك للاستفادة بها في المستقبل وخاصة في الأغراض العلمية. (طلعت مصطفى السروجي، القاهرة، ع . . ب) 
ثالثاً: أدوات جمع البيانات: اتساقاً مع متطلبات الدراسة الراهنة فقد اعتمد الباحث علي أكثر من أداة لجمع بياناته من الميدان، مع مراعاة:

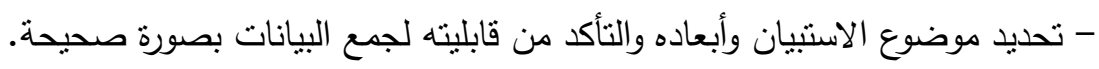
- الرجوع إلى الدراسات السابقة والكتابات النظرية والنظريات العلمية المتعلقة بالدراسة الحالية

$$
\text { للتنوصل إلى فقرات الاستبيان. }
$$$$
\text { - تحديد أوزان العبارات في الاستبيان. }
$$

- اختبار الصدق الظاهري للاستبيان بعرضه على مجموعه من المحكمين لا تقل درجتهم

$$
\text { العلمية عن أستاذ. }
$$

- إجراء الصدق الإحصائي بعد التعديل بناءاً على نتائج الصدق الظاهري.

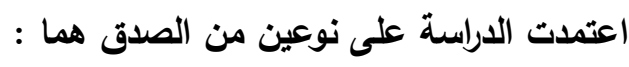

الصدق الظاهرى: وقد قام الباحث فى إطار مراعاة الصدق الظاهرى بعرض استمارة الاستبيان

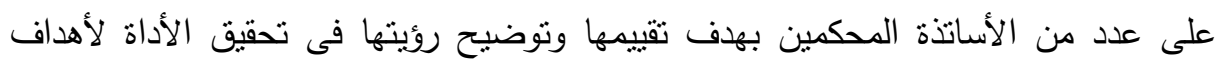
البحث، وقد استفاد الباحث من ملاحظات المحكمين الذين قاموا بالاطلاع على الأستبيان، وكانت لهم ملاحظات تم تعديلها كما قام الباحث بإجراء دراسة استطلاعية على . r مفردة

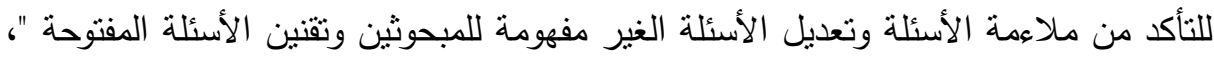

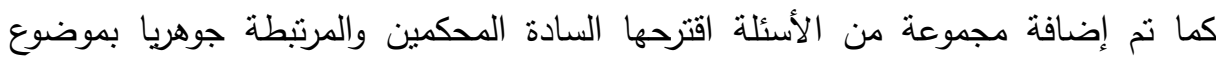

$$
\text { البحث. }
$$

الثبات: ويقصد به ثبات الاستجابات فى حالة تكرار تطبيق الإداة بمعنى عدم التغير جوهريا،

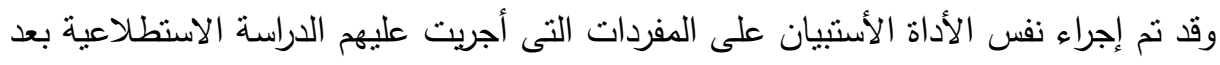
عثرة أيام من الدرسة الاستطلاعية وتم حساب معامل الارتباط بين الاستجابات فى التطبيق الجنيق

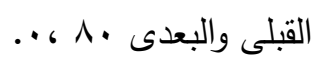

وقد قام الباحثون باتباع تلك الخطوات في إعداد الاستبيان، مع مراعاة ما يلي:

$$
\text { ( (1) (1) تحديد موضوع الاستنيان وأبعاده. }
$$

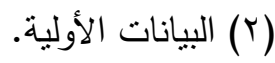


(r) شبكات التواصل الاجتماعي واليات الترابط والتفكك بين الثباب.

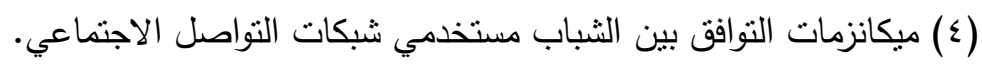

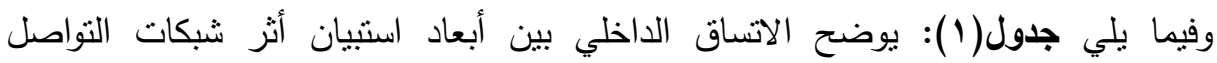
الاجتماعي في تدعيم آليات الترابط والتفكك لدى الثنباب الجامعي ودرجة الاسنبيان ككل

\begin{tabular}{|c|c|c|c|}
\hline الدلالة & معامل الارتباط & المتغير & م \\
\hline ** & $\cdot, V \backslash r$ & العلاقات الاجتماعية & 1 \\
\hline$* *$ & $\cdot, V \leq V$ & ميكانيزمات التوافق الأسري & r \\
\hline ** & $\cdot, \wedge \leqslant 1$ & ميكانزمات التوافق الاجتماعي & r \\
\hline *** & $\cdot, V Y O$ & ميكانزمات النوافق الأكاديمي. & $\varepsilon$ \\
\hline
\end{tabular}

* دالة عند مستوى معنوية (0., (•) *** دالة عند مستوى معنوية (1 (•, )

يتضح من الجدول رقم (1) أن معظم متغيرات الاستبيان دالة عند مستويات الدلالة المتعارف عليها لكل بعد على حدا، ومن ثم يمكن القول إن درجات العبارات تحقق الحد الذي يمكن معه قبول هذه الدرجات ومن ثم تحقق مستوى الثقة في الأداة والاعتماد على نتائجها. 1-مقياس أثز شبكات التواصل الاجتماعي في تدعيم آليات الترابط والتفكك لدى الثباب

$$
\text { الجامعي }
$$

فيما يلي تحليل البيانات الإحصائية للاستبيان جايت على النحو التالي:

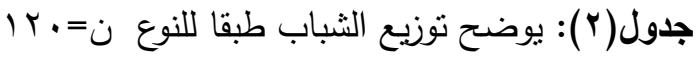

\begin{tabular}{|c|c|c|c|}
\hline$\%$ & ك & النوع & م \\
\hline vo & 9. & ذكر & 1 \\
\hline ro & r. & أنثى & $r$ \\
\hline$\% 1 \ldots$ & Ir. & & \\
\hline
\end{tabular}




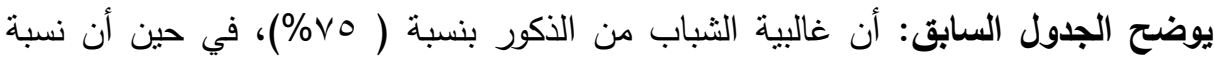
الإناث (Yo\%) وقد يرجع ذللك إلى اهتمام بشبكات التواصل الاجتماعي أكثر من الإناث.

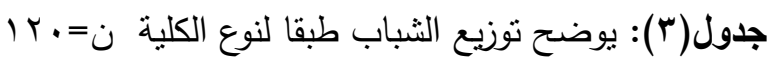

\begin{tabular}{|c|c|c|}
\hline النسبة \% & التكرار & نوع الكلية \\
\hline$v \cdot, \cdots$ & $\wedge \varepsilon$ & إنسانية \\
\hline$r \cdot,$. & Tr & علمية \\
\hline$\% 1 \ldots$ & Ir. & المجموع \\
\hline
\end{tabular}

يوضح الجدول السابق أن: أن أكبر نسبة من الثباب ينتمون إلى الكليات الإنسانية بنسبة

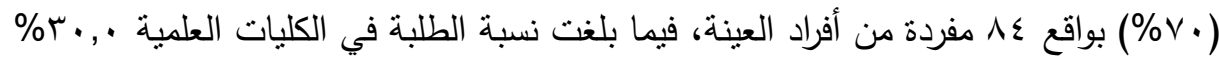
بواقع بr مفردة،

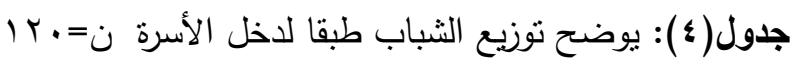

\begin{tabular}{|c|c|c|c|}
\hline النسبة\%\% & التكرار & دخل الأسرة الشهري & 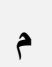 \\
\hline $11,7 \mathrm{~V}$ & $1 \varepsilon$ & أقل من ( . . ץ) دينار & 1 \\
\hline$r \varepsilon, I V$ & rq & 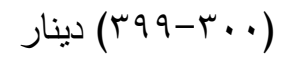 & ب \\
\hline $1 v, 0$ & r) & 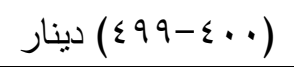 & ج \\
\hline$\varepsilon 7, T \vee$ & 07 & ( . • (0) دينار فأكثر & נ \\
\hline$\% 1 \ldots$ & $k$. & 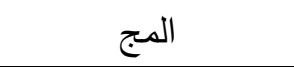 & \\
\hline
\end{tabular}

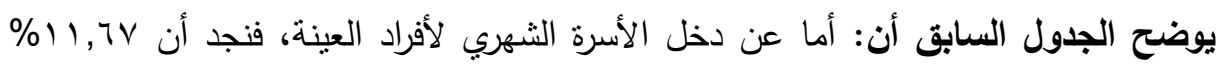

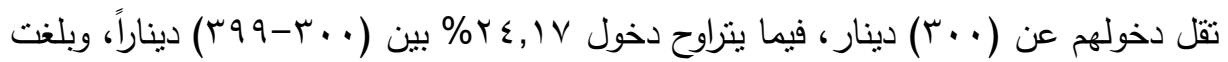

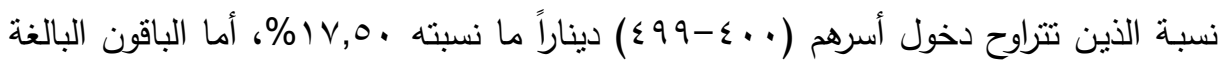

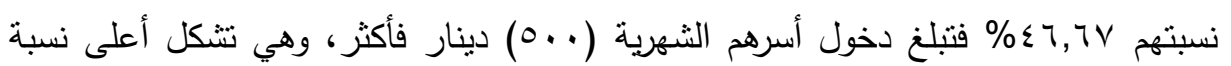
من حيث الدخل الثهري. 
جدول(ه): يوضح توزيع الثباب طبقاً لكيفية تعلم استخدام شبكات التواصل الاجتماعي Ir. $=$ ن

\begin{tabular}{|c|c|c|c|}
\hline النسبة \% & 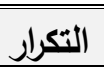 & كيفية تعلم استخدام الإنترنت & م \\
\hline 10.00 & ir & دورة تدريبية & 1 \\
\hline 4.17 & 0 & أحد الوالدين & ب \\
\hline 12.50 & 10 & أحد الأخوة & ج \\
\hline 14.17 & iv & أحد الأصدقاء & $د$ \\
\hline 55.83 & $7 \mathrm{~V}$ & تعلم ذاتي & هـ \\
\hline 3.33 & $\varepsilon$ & أخرى & و \\
\hline $1 \ldots$ & $i r$. & المجموع & \\
\hline
\end{tabular}

يوضح الجدول السابق أن: عدد من السلوكيات الخاصة بمستخدمي شبكات التواصل الاجتماعي، حيث نظهر البيانات الواردة فيه أن •,.•1\% من أفراد العينة تعلموا استخدام

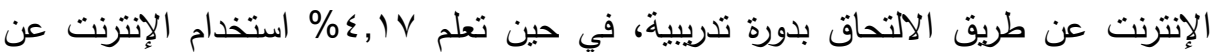

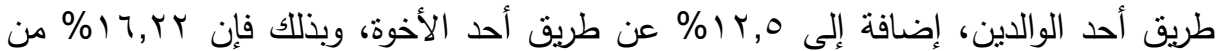
أفراد العينة قد تعلموا استخدام الإنترنت عن طريق الأسرة، وهذا يشير إلى ضعف دور الوالدين

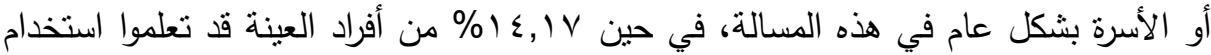

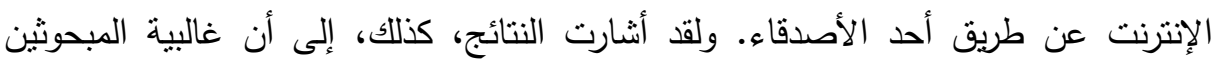
r ب00, تعلموا استخدام الإنترنت عن طريق التعلم الذاتي. ومن أهم نتائج الدراسة الخاصة بتحديد أثز استخدام الثباب لثبكات التواصل الاجتماعي على ميكانيزمات العلاقات الاجتماعية. 
جدول(†): يوضح نوزيع الثباب طبقاً لكيفية تعلم استخدام شبكات التواصل الاجتماعي $1 \mathrm{r} \cdot \dot{0}$

\begin{tabular}{|c|c|c|c|}
\hline النسبة \% & الت التكرار & كيفية تعلم استخدام الإنترنت & b \\
\hline 10.00 & it & دورة تدريبية & 1 \\
\hline 4.17 & o & أحد الوالدين & ب \\
\hline 12.50 & 10 & أحد الأخوة & 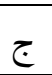 \\
\hline 14.17 & IV & أحد الأصدقاء & د \\
\hline 55.83 & TV & تعلم ذاتي & ه \\
\hline 3.33 & $\varepsilon$ & أخرى & 9 \\
\hline $1 \ldots$ & 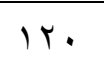 & المجموع & \\
\hline
\end{tabular}

يوضح الجدول السابق أن: عدد من السلوكيات الخاصة بمستخدمي شبكات التواصل الاجتماعي، حيث تظهر البيانات الواردة فيه أن ·,.•1\% من أفراد العينة تعلموا استخدام الإنترنت عن طريق الالتحاق بدورة تدريبية، في حين تعلم

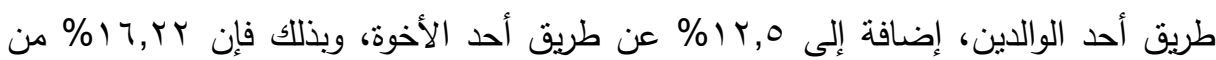

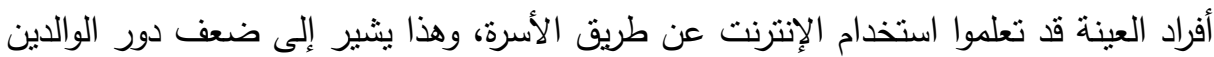

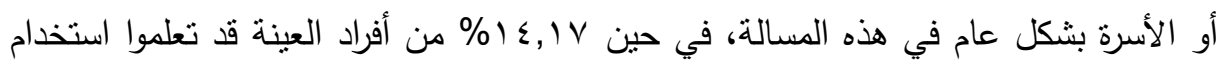

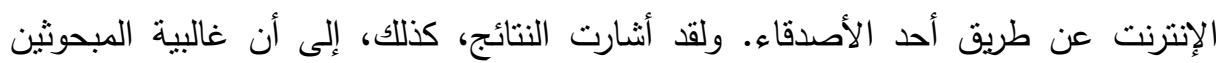
ץ \% \% \% تعلموا استخدام الإنترنت عن طريق التعلم الذاتي. 


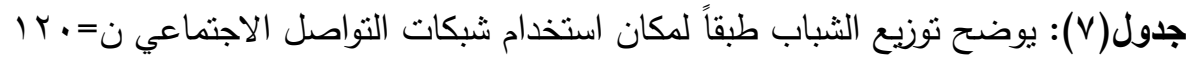

\begin{tabular}{|c|c|c|c|}
\hline النسبة \% & التكرار & مكان استخدام شبكات التواصل & م \\
\hline 31.67 & rᄉ & المنزل & 1 \\
\hline 37.50 & $\leqslant 0$ & الجامعة & ب \\
\hline 2.50 & $r$ & عند أحد الأصدقاء & ج \\
\hline 21.67 & YY & في أحد المقاهي & د \\
\hline 6.67 & $\Lambda$ & أخرى & ه \\
\hline $1 \ldots$ & $1 \%$. & المجموع & \\
\hline
\end{tabular}

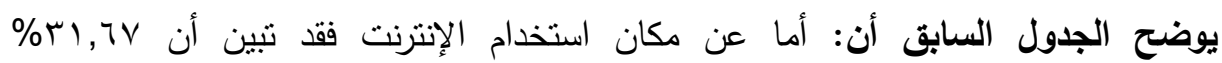
يستخدمونه في منازلهم، وان أكثر من بr.0\% يستخدمونه في الجامعة، وذللك نظراً لتوفر المختبرات الحاسوبية في جميع الكليات داخل الحرم الجامعي، وتوفر الخدمة المجانية

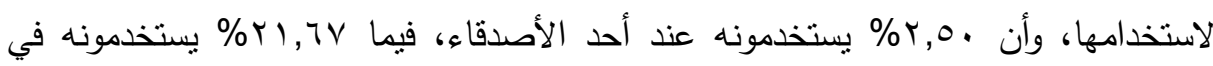
المقاهي الخاصة بذللك. جدول (^): يوضح توزيع الثباب طبقا للفترة الزمنية التي يقضونها على شبكات التواصل

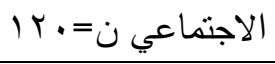

\begin{tabular}{|c|c|c|c|}
\hline$\%$ & ك & الفترة الزمنية & 5 \\
\hline$\varepsilon 9,1 v$ & 09 & أقل من ساعتين يوميا & 1 \\
\hline MI,TV & rᄉ & من ساعتين إلى أقل من ع ساعات يوميا & $r$ \\
\hline $19,1 \mathrm{~V}$ & rr & أكثر من ع ساعات & $r$ \\
\hline$\% 1 \ldots$ & ir. & مج & \\
\hline
\end{tabular}

يوضح الجدول السابق: أن أكبر نسبة من الثباب بمجتمع الدراسة في مدة استخدام شبكات

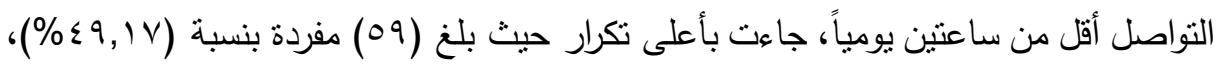

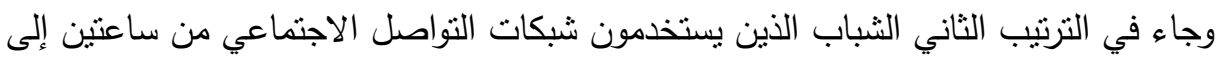

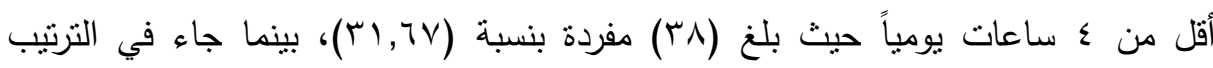

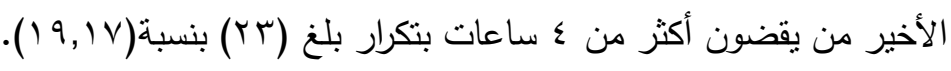


جدول(9): المتوسطات الحسابية والانحرافات المعيار لمستوى ميكانيزمات التوافق النفسي لدى

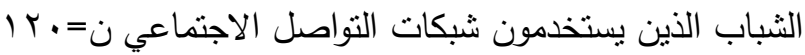

\begin{tabular}{|c|c|c|c|c|c|}
\hline المستوى & الالمعياري & الحسابي & الرتبة & الفترة الزمنية & r \\
\hline مرتقع & $\cdot, 7$. & $\cdot, 9 \leq r$ & 1 & ميكانيزمات التوافق الأسربي & 1 \\
\hline مرتفع &., 79. & • & $r$ & مبكانيزمات التوافق الأكاديمي & $r$ \\
\hline مرتقع & $\cdot, \leqslant 9$. & $\cdot$, vor & r & ميكانيزمات التوافق الاجتماعي & r \\
\hline مرتقع & $\cdot, 0 \leqslant$. & $\cdot, v \leq r$ & $\varepsilon$ & ميكانيزمات التوافق الثخصي & $\varepsilon$ \\
\hline مرتقع & $\cdot, \varepsilon r$. & $\cdot, \Lambda \cdot r$ & & الدرجة الكلية & \\
\hline
\end{tabular}

يوضح الجدول السابق: أن المتوسط الحسابي الكلي للتوافق النفس للثباب الذين يستخدمون

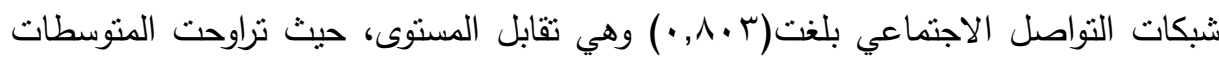

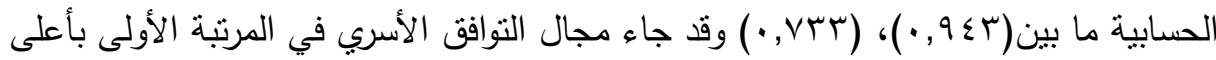

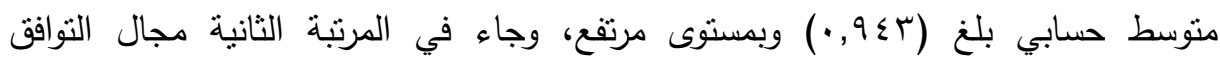

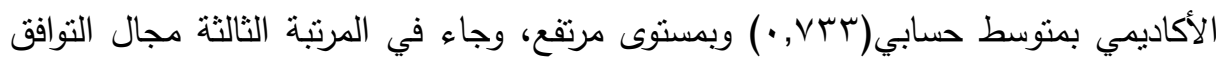

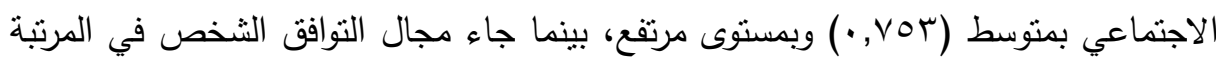

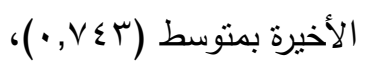


ثانياً: أثر استخدام الثباب لثبكات التواصل الاجتماعي على ميكانيزمات العلاقات الاجتماعية.

جدول رقم( • ): التوزيع عينة الدراسة حسب أثر استخدام الإنترنت على العلاقات الاجتماعية

\begin{tabular}{|c|c|c|c|c|c|c|c|c|c|}
\hline التربتب & المعياري & الحسابطي & بثارض & معارض & محايد & موافق & مبثدة & الفقرات & م \\
\hline 1 & I, & r, ro & צ & ז,. & $1 \cdot, v$ & $1 \cdot, 0$ & $11, \varepsilon$ & 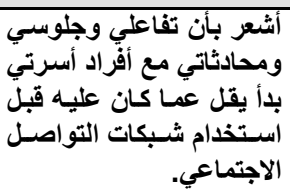 & 1 \\
\hline 0 & 1,17 & $r, . q$ & ד, & $r q, v$ & $\mathrm{v}, 1$ & $11, \mathrm{~V}$ & $\varepsilon, q$ & 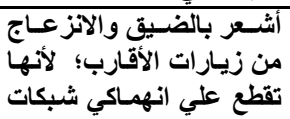 & $r$ \\
\hline$\varepsilon$ & 1,00 & $r, 17$ & $r q, 0$ & $\leqslant 1,7$ & $1 \leqslant, r$ & Ir, 9 & $1, \wedge$ & 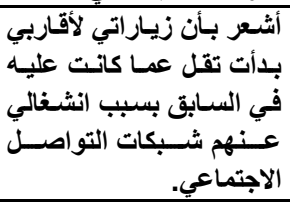 & $r$ \\
\hline r & 1,10 & $r, Y)$ & r & $\lceil\wedge, \wedge$ & $\wedge, q$ & $1 \wedge, r$ & $r, 0$ & 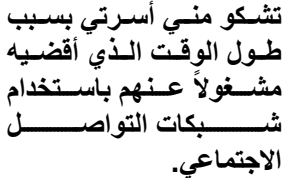 & $\varepsilon$ \\
\hline r & $1, r_{1}$ & r, ro & $r q, 0$ & $\varepsilon r, v$ & $\mathrm{v}, 1$ & Ir,. & $v, v$ & 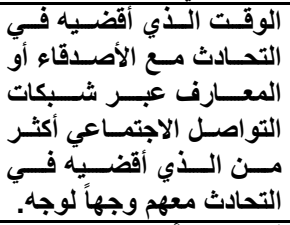 & 0 \\
\hline V & $\cdot, 9 \vee$ & 1,90 & r,v & $\leqslant 1, \wedge$ & $I_{1}, 9$ & $7, \wedge$ & $1, \wedge$ & 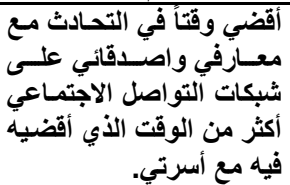 & 7 \\
\hline 7 & $1, \cdot \varepsilon$ & $r, . T$ & Tr, & $\leq 7,1$ & $\vee, \vee$ & 11,1 & $r, \Lambda$ & 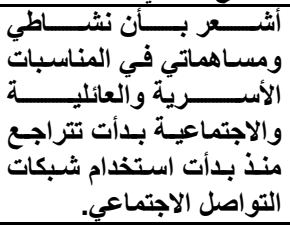 & $V$ \\
\hline & $\cdot, 10$ & $r, 10$ & $r, O$ & $\varepsilon 1, \varepsilon$ & $9, \wedge$ & 11,9 & $\varepsilon, V$ & جميع الفقرات & \\
\hline
\end{tabular}

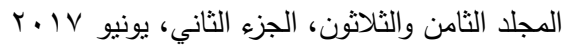


يوضح الجدول السابق : للتعرف إلى مدى أثز استخدام شبكات التواصل الاجتماعي على

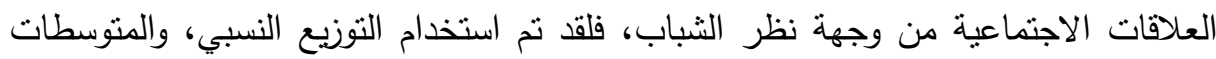
الحسابية، والانحرافات المعيارية لإجابات أفراد العينة على الفقرات المتعلقة بأثر استخدام شبكات التواصل الاجتماعي على العلاقات الاجتماعية.

تظهر بيانات الجدول أن إجابات أفراد العينة على الفقرات المتعلقة بالهاتهاتهات

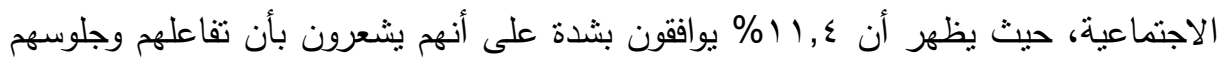

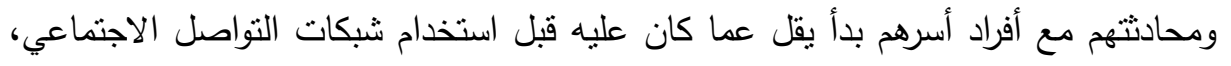

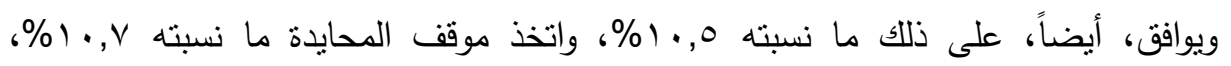

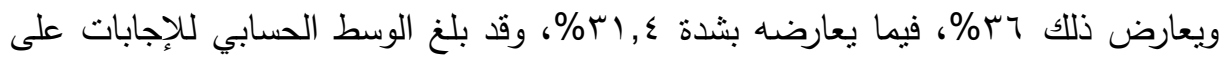

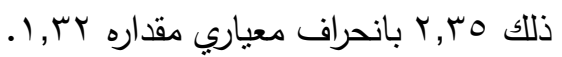
أما عن شعور أفراد العينة بالضيق والانزعاج من زيارات الأقارب؛ لأنها تقطع عليهم

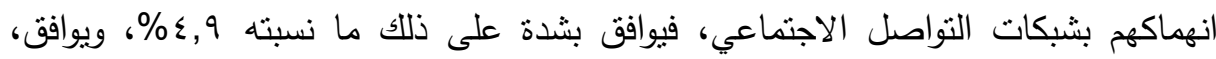

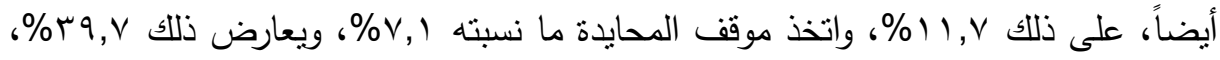

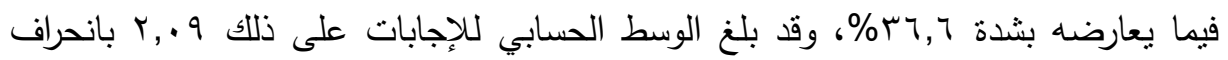

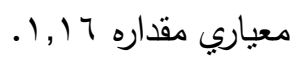
وفيما يتعلق بشعور أفراد العينة بأن زياراتهم لأقاربهم بدأت نقل عما كانت عليه في

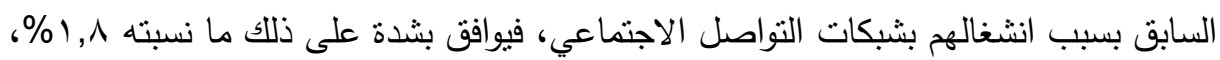

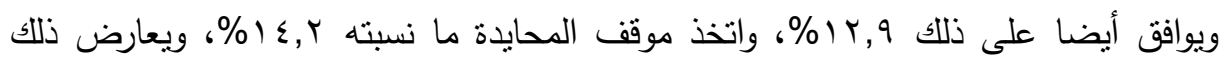

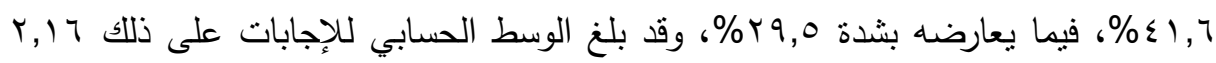
بانحراف معياري مقداره 0 ., 1. وفيما يتعلق بالوقت الذي يقضيه أفراد العينة في التحادث مع الأصدقاء أو المعارف عبر

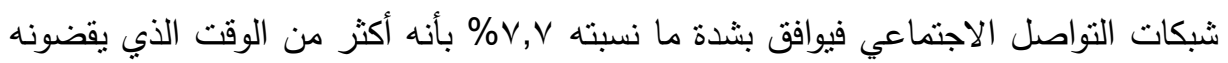

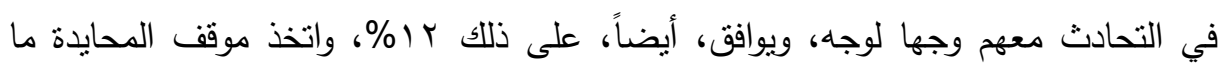




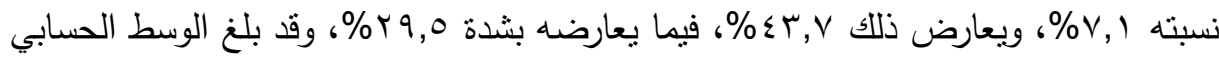

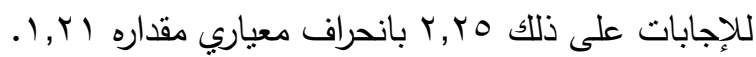

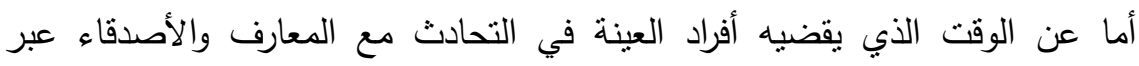
شبكات التواصل الاجتماعي أكثر من الوقت الذي يقضونه مع أسرهم، فيوافق بشدة على ذلك

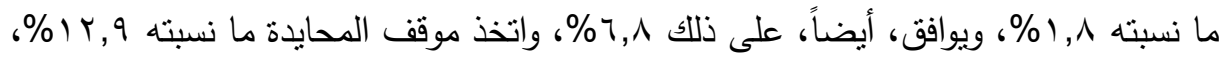

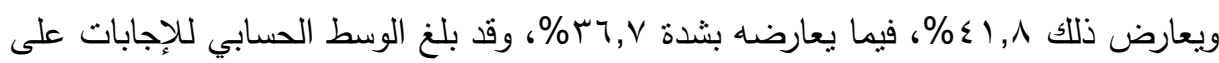

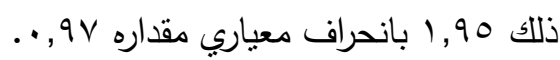
وفيما يتعلق بشعور أفراد العينة بأن نشاطهم ومساهماتهم في المناسبات الأسرية العائلية

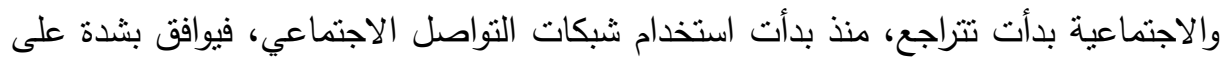

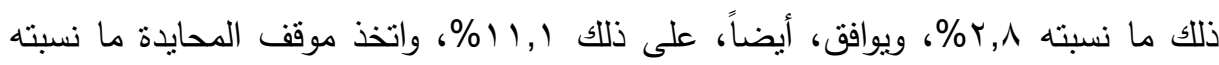
\% \%,V

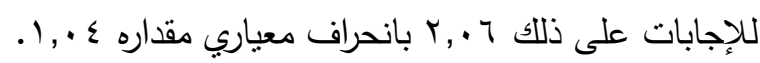

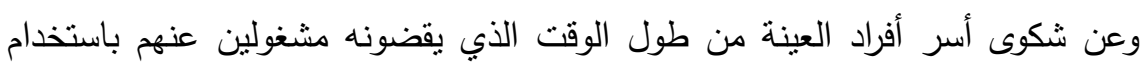

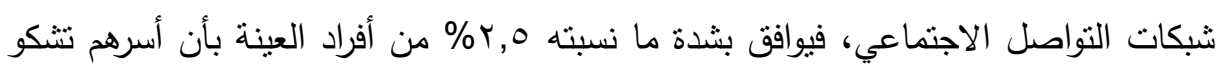

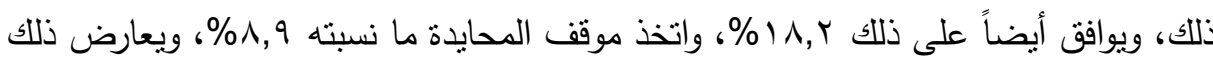

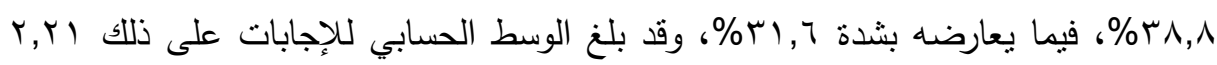
بانحراف معياري مقداره 0 1, 1.

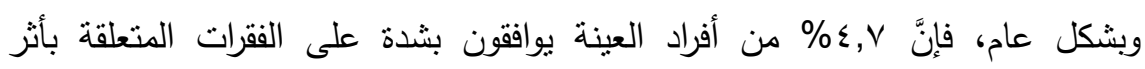
استخدام شبكات التواصل الاجتماعي على العلاقات الاجنماعية، كما ويوافق عليها أيضاً

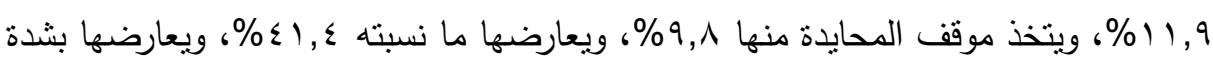

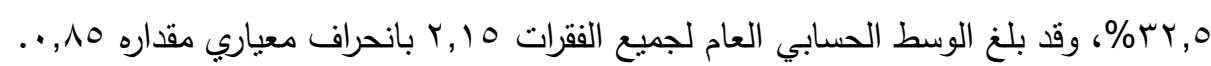

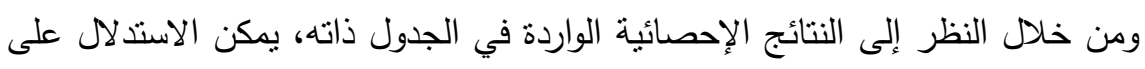
أن أثز استخدام شبكات التواصل الاجتماعي على مجمل العلاقات الاجتماعية لأفراد عينة الإنة 
الدراسة لم يكن سلبياً بشكل عام، حيث بلغ الوسط الحسابي العام لجميع الفقرات دون المتوسط، وهذا يشير إلى أن الأثر السلبي لاستخدام الإنترنت على العلاقات الاجتماعية

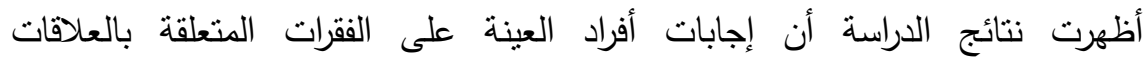
الاجتماعية، حيث يظهر أن ع,11\% 1 بوافقون بشدة على أنهم يشعرون بأن تفاعلهم وجلوسهر

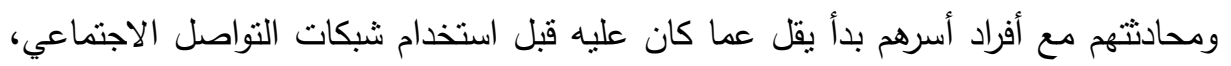

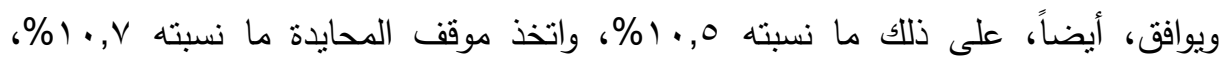

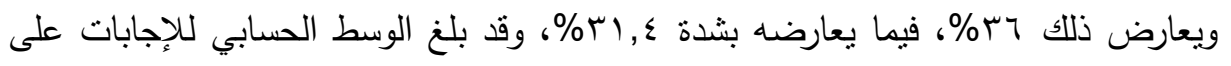

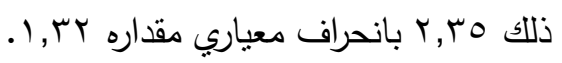
أما عن شعور أفراد العينة بالضيق والانزعاج من زيارات الأبرات الأقارب؛ لأنها تقطع عليهم

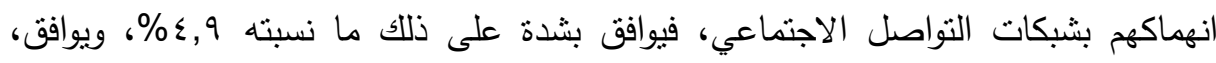

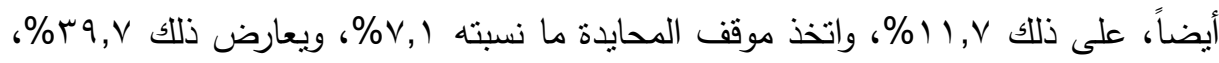

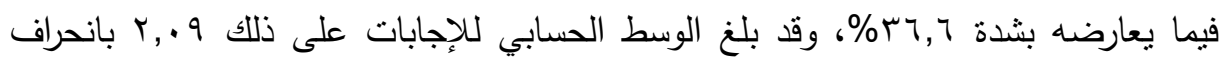

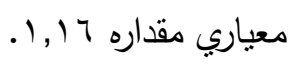

وفيما يتعلق بشعور أفراد العينة بأن زياراتهم لأقاربهم بدأت نقل عما كانت عليه في

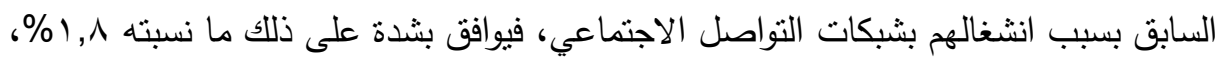

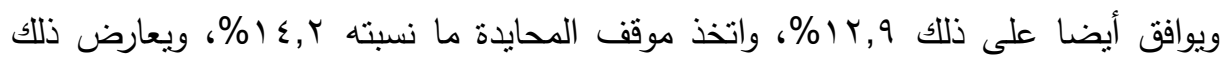

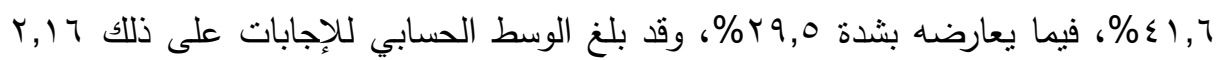

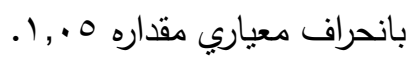

وفيما يتعلق بالوقت الذي يقضيه أفراد العينة في التحادث مع الأصدقاء أو المعارف عبر

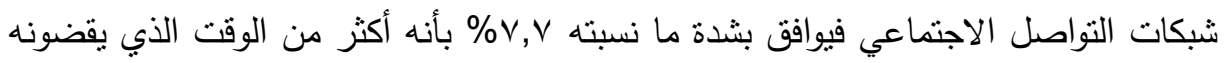

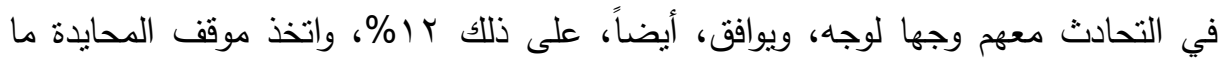

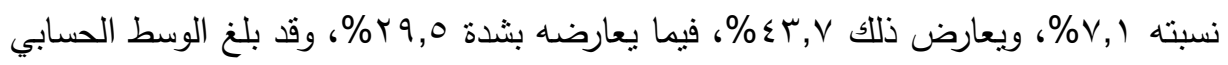

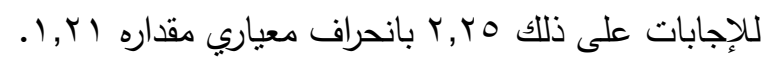


أما عن الوقت الذي يقضيه أفراد العينة في التحادث مع المعارف والأصدقاء عبر شبكات التواصل الاجتماعي أكثر من الوقت الذي يقضونه مع أسرهم، فيوافق بشدة على ذلك فئه

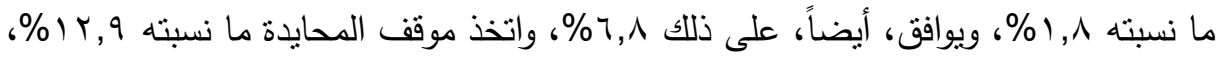

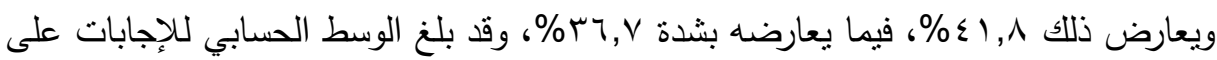

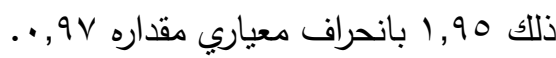

وفيما يتعلق بشعور أفراد العينة بأن نشاطهر ومساهماتهم في المناسبات الأسرية العائلية

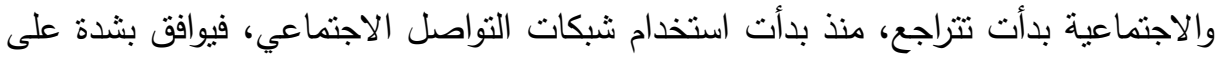

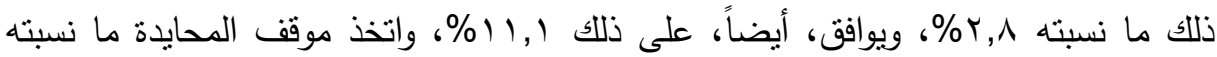
\% \%,V

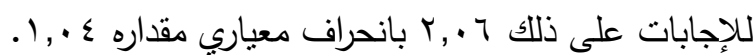

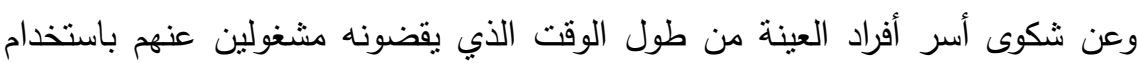

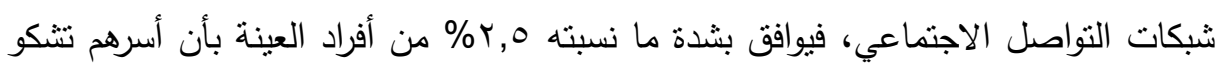

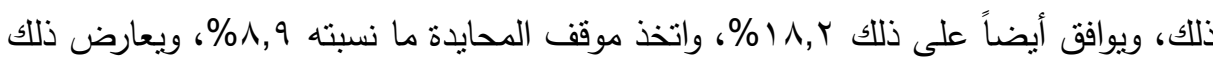

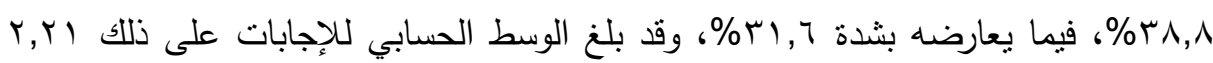

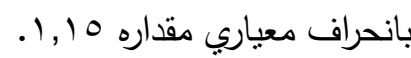

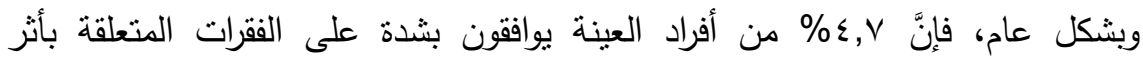
استخدام شبكات التواصل الاجتماعي على العلاقات الاجتماعية، كما ويوافق عليها أيضاً

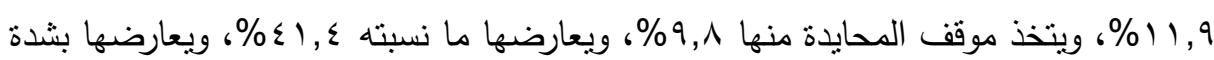

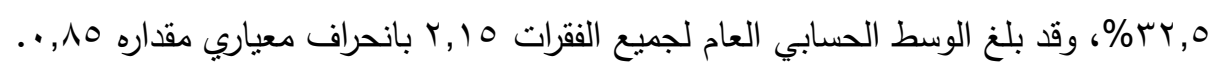

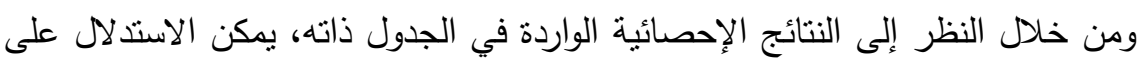

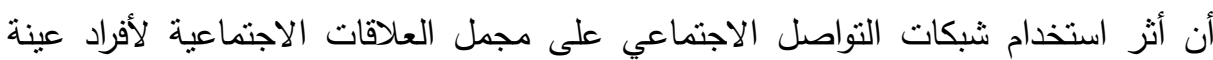

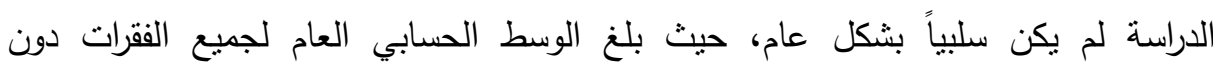
المتوسط، وهذا يثير إلى أن الأثز السلبي لاستخدام الإنترنت على العلاقات الاجنماعية 
كذلك عرض نتائج الدراسة المرنبطة بآليات التوافق لاى الثباب الجامعي مستخدمي شبكات التواصل الاجتماعي. أ- عرض نتائج الدراسة المرتبطة بآليات التوافق الشخصي. جدول(•r): يوضح الفروق بين النوع في ميكانيزمات النوافق الثخصي لدى الثنباب

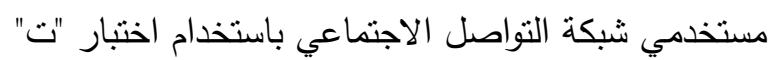

\begin{tabular}{|c|c|c|c|c|c|c|c|}
\hline الإحصائية & الحرية & قيمة"ت" & الالمعراف & الحسابي & العدد & النوع & المجال \\
\hline \multirow{2}{*}{$\cdot, \cdot 0$} & \multirow{2}{*}{111} & \multirow{2}{*}{$r, 701$} & $r, 0$ & $r, \uparrow \wedge$ & 9. & ذكر & \multirow{2}{*}{ النخصافق } \\
\hline & & & $\varepsilon, 0$ & $r, 19$ & $r$. & أنثي & \\
\hline
\end{tabular}

يوضح الجدول السابق: أنه نوجد فروق دالة إحصائياً عند مستوى معنوية (ه.,. •) بين الذكور والإناث في ميكانيزمات النوافق الثخصي لدى الثباب المستخدم لثبكات التواصل الاجتماعي لصالح الذكور

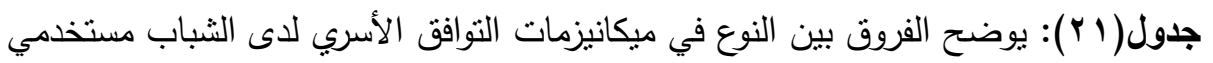
شبكة التواصل الاجتماعي باستخدام اختبار "ت"

\begin{tabular}{|c|c|c|c|c|c|c|c|}
\hline الإحصائية & الدرية & قيمة"ت" & الانعراف & الحسابي & العدد & النوع & المجال \\
\hline \multirow{2}{*}{$\cdot, .0$} & \multirow{2}{*}{111} & \multirow{2}{*}{$\Gamma, \Gamma \leqslant-$} & 7,7 & $\cdot, r \wedge \wedge$ & 9. & ذكر & \multirow{2}{*}{ الأسروي } \\
\hline & & & 0,0 & $1, \cdot \varepsilon$ & r. & أنثى & \\
\hline
\end{tabular}

يوضح الجدول السابق: أنه توجد فروق دالة إحصائياً عند مستوى معنوية (0., •) بين

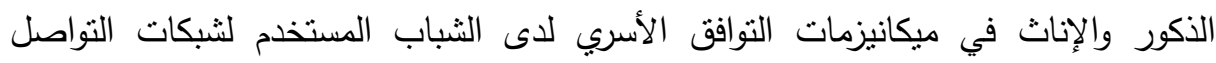

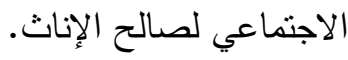


جدول(Y): يوضح الفروق بين النوع في ميكانيزمات التوافق الاجتماعي لاى الثباب

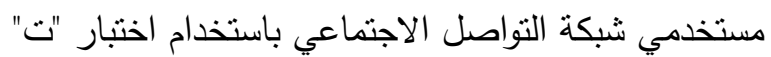

\begin{tabular}{|c|c|c|c|c|c|c|c|}
\hline الإحصائية & الحرجة & قيمة"ت" & الانعبراف & الحستوسط & العدد & النوع & المجال \\
\hline \multirow{2}{*}{$\cdot, .0$} & \multirow{2}{*}{111} & \multirow{2}{*}{, 071} & 0,0 & $r, r T$ & 9. & ذكر & \multirow{2}{*}{ الاجتماعى التق } \\
\hline & & & $\varepsilon, Y$ & $\Gamma, \wedge r$ & $\mu$. & أنثىي & \\
\hline
\end{tabular}

يوضح الجدول السابق: أنه توجد فروق دالة إحصائياً عند مستوى معنوية (ه.,.•) بين الذكور والإناث في ميكانيزمات التوافق الاجتماعي لدى الثباب المستخدم لثبكات التواصل

$$
\text { الاجتماعي لصالح الإناث. }
$$

جدول(Yr): يوضح الفروق بين النوع في ميكانيزمات التوافق الاجتماعي لدى الثباب النب مستخدمي شبكة التواصل الاجتماعي باستخدام اختبار "ت"

\begin{tabular}{|c|c|c|c|c|c|c|c|}
\hline الإحصائية & الحرية & قيمة"ت" & الانحراف & الحستوسط & العدد & النوع & المجال \\
\hline \multirow{2}{*}{$\cdot, .0$} & \multirow{2}{*}{111} & \multirow{2}{*}{, 07} & 0,0 & $r, Y T$ & 9. & ذكر & \multirow{2}{*}{ الاجتماعى التوافق } \\
\hline & & & $\varepsilon, Y$ & r,А & $r$. & أننتي & \\
\hline
\end{tabular}

يوضح الجدول السابق: أنه توجد فروق دالة إحصائياً عند مستوى معنوية (0., •) بين الذكور والإناث في ميكانيزمات التوافق الاجتماعي لدى الثباب المستخدم لثبكات التواصل الاجتماعي لصالح الإناث. جدول(؟r): يوضح الفروق بين النوع في ميكانيزمات التوافق الأكاديمي لاى الثباب مستخدمي شبكة التواصل الاجتماعي باستخدام اختبار "ت"

\begin{tabular}{|c|c|c|c|c|c|c|c|}
\hline الإحصائية & الحرية & قيمة"ت" & الالمعراف & الحستوسطي & العدد & النوع & المجال \\
\hline \multirow{2}{*}{$\cdot, .0$} & \multirow{2}{*}{111} & \multirow{2}{*}{$\varepsilon, 1 Y \tau$} & $\Lambda, \vee$ & $r, 0 \Lambda$ & 9. & ذكر & \multirow{2}{*}{ الأكاديمى } \\
\hline & & & $r, 7$ & $r, \wedge \wedge$ & $r$. & أنتي & \\
\hline
\end{tabular}

يوضح الجدول السابق: أنه توجد فروق دالة إحصائياً عند مستوى معنوية (0.,. •) بين

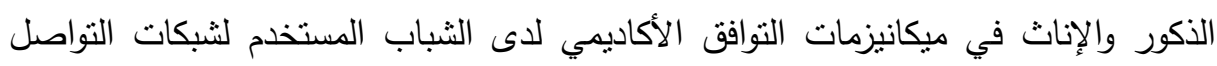
الاجنماعي لصالح الإناث. 
أظهرت نتائج الدراسة أن المتوسطات الحسابية لفقرات آليات التوافق الثخص قد تراوحت

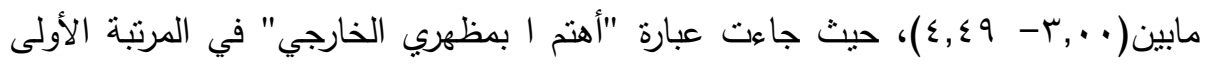

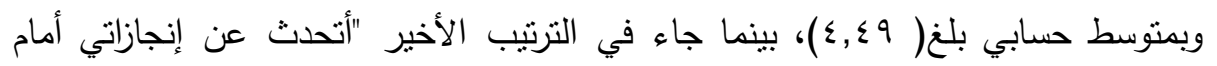

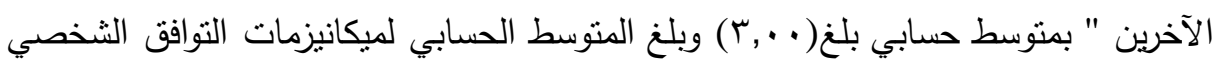

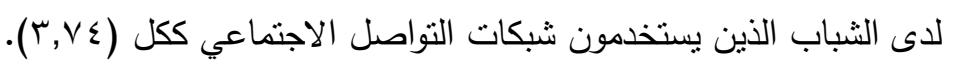

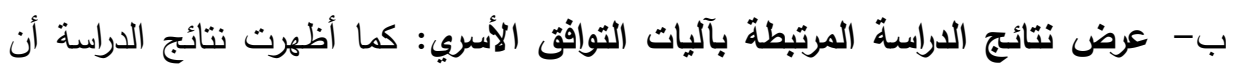

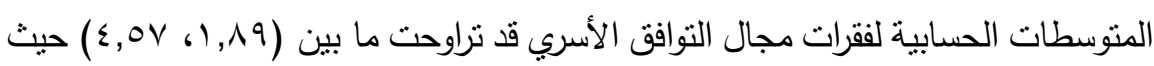

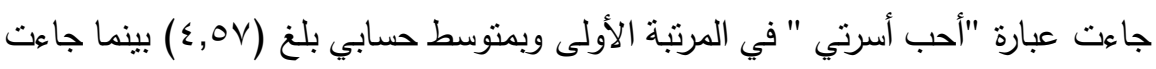
عبارة "أنثعر برغبة شديدة في الهروب من المنزل " بالمرنبة الأخيرة وبمنوسط حسابي

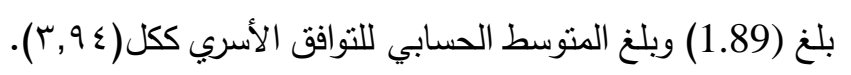

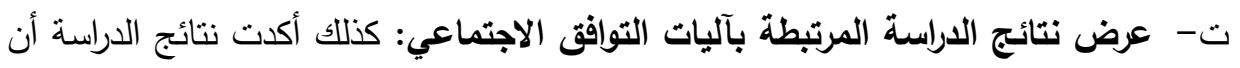

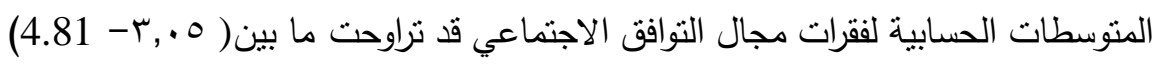

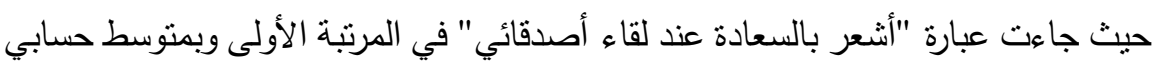

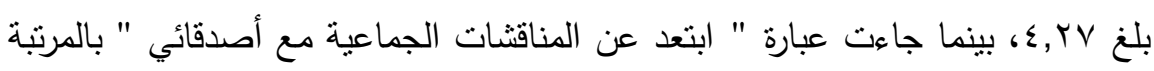

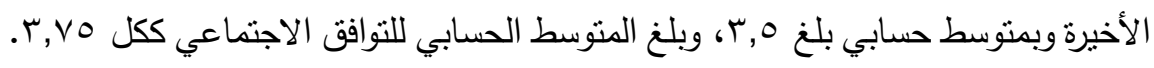

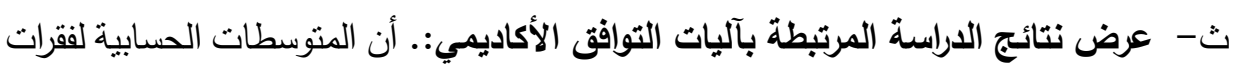

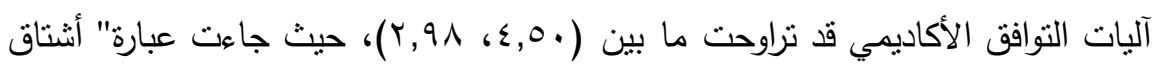

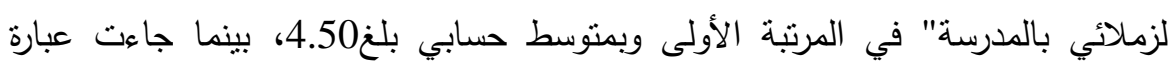

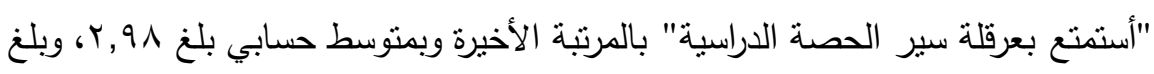

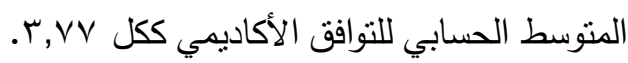
عرض نتائج الدراسة الخاصة بطبيعة العلاقة بين مستوى التوافق والفترة الزمنية للثباب في استخدام شبكات التواصل الاجتماعي. 
أكدت نتائج الدراسة علي وجود علاقة سلبية ذات دلالة إحصائية (م= 15 ـ 1 1) بين

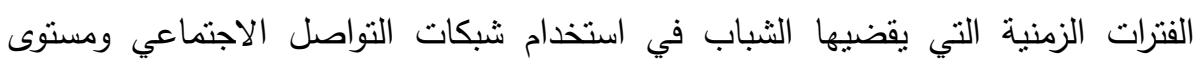

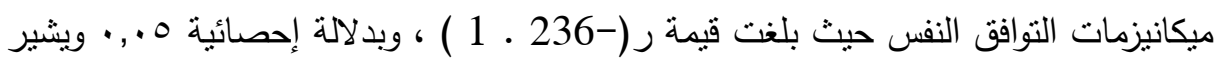

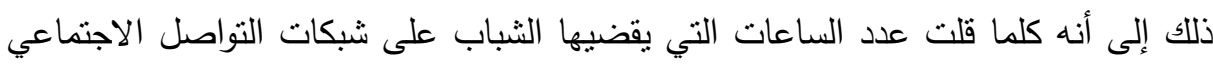

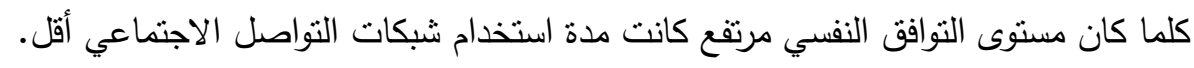

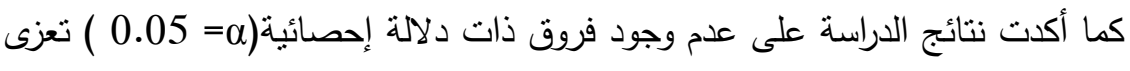

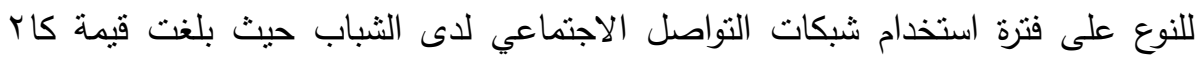
(0.845) وبدلالة إحصائية( • rا, •).)

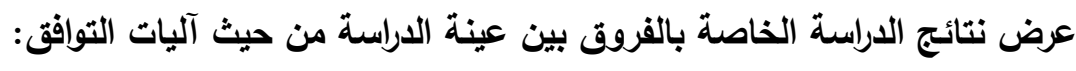

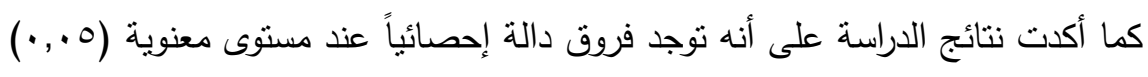

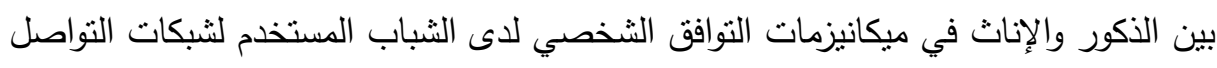
الاجتماعي لصالح الذكور

كما أكدت نتائج الدراسة على أنه نوجد فروق دالة إحصائياً عند مستوى معنوية (0. . . )

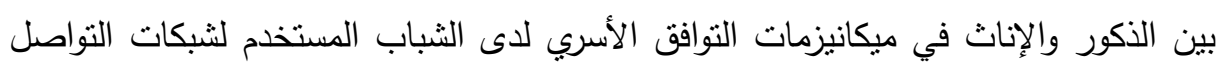
الاجتماعي لصالح الإناث. كما أكدت ننائج الدراسة على أنه توجد فروق دالة إحصائياً عند مستوى معنوية (0. . . )

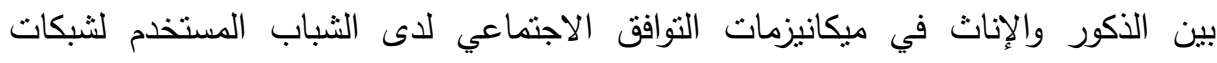
التواصل الاجتماعي لصالح الإناث.

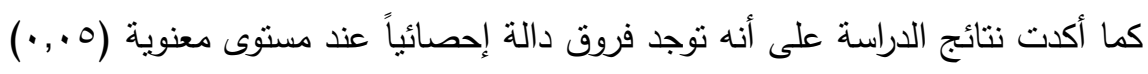

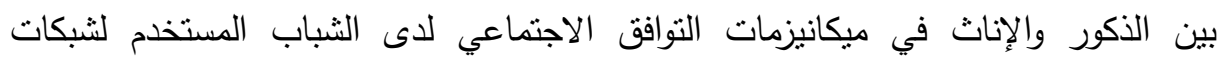

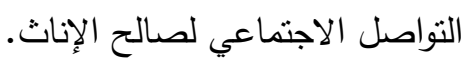

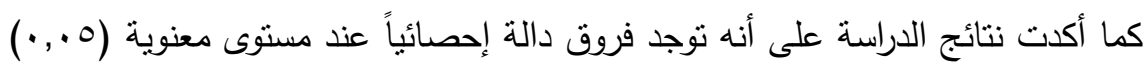

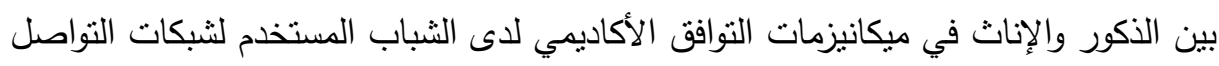

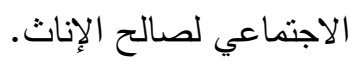




\section{المراليع}

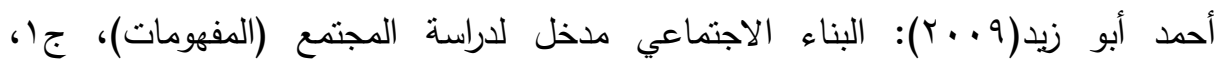

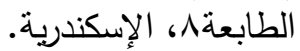

آمال صادق، وفؤاد أبو حطب(·99 (19): نمو الإنسان من مرحلة الجنين إلي مرحلة المسنين،

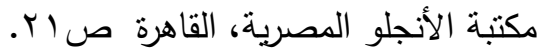

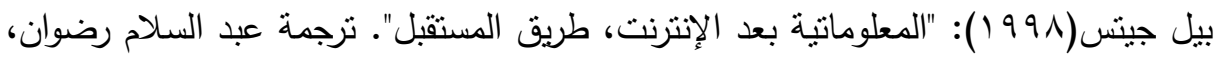

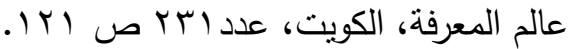

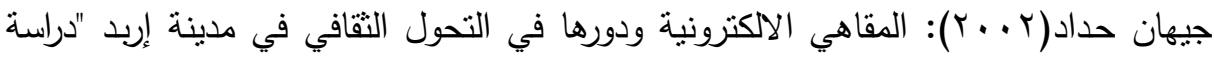

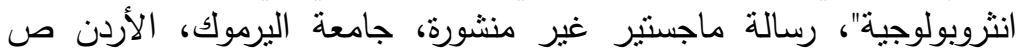

$$
\text { .r. }
$$

Spiro, R,(1991): cognitive flexibility Constructivism and hyper text. Journal of Educational Technology Vol.88, No.(1)., pp2937

Appleton , k(1997),: Analysis and description of students learning during science classes using a constructivist -based model. Journal of Research in science teaching. Vol.34, No. (3), pp 302-323. 
فاطمة يوسف القليني وآخرون

\title{
THE IMPACT OF SOCIAL NETWORKING TO STRENGTHEN THE MECHANISMS OF COHERENCE AND DISINTEGRATION AMONG KUWAIT YOUTH NETWORKS AN APPLIED STUDY ON THE STUDENTS OF KUWAIT UNIVERSITY
}

\author{
Elkelliny, Fatma, Y.(1); Shamrokh, Mervat, G. ${ }^{(2)}$; \\ Elrihan, A. H. ${ }^{(3)}$ and Al-barazi, B. A. A. ${ }^{(4)}$
}

1) Faculty of, Ain Shams University 2) Faculty of Social Work, Helwan University 3) Media Department, Kuwait University 4) Kuwaiti Armed Forces

\begin{abstract}
This study belongs to the pattern of analytical descriptive studies as the most appropriate types of studies suitable to the nature of the subject of the study, which aims to describe and analyze the impact of social networks on the mechanisms of interdependence and disintegration among young people, and then we can get facts through the information and interpretation and then extract and achieve the most benefit, The study is one of the descriptive studies that measure the relationship between two independent variable variables. The social networks and the dependent variable are the mechanisms of interconnection and disintegration among the Kuwaiti youth. They are the most appropriate types of studies to achieve the objectives of the current study. The study used the questionnaire, which included, in addition to the initial data, 14 questions that tried to reach the mechanisms of compatibility between young users of the social networks, society, family and comrades, in order to collect data in terms of the theory of ecological pattern, cognitive theory and behavioral

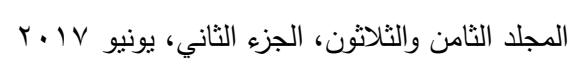


theory. The sample size of the study was (120) individuals of university youth, which uses social networks. The main results of the study were to confirm the existence of a negative relation with statistical significance $(1.15=\alpha)$ between the periods of time spent by young people in the use of social networks and the level of mechanisms of self-discrepancy where the value of $(1$ - 236), and a statistical significance 0.05 This indicates that the smaller the number of hours spent on social networks, The results of the study showed that there were no statistically significant differences $(0.05=\alpha)$ due to the type of social networks used in young people. The value of Ka 2 (0.845) and statistical significance (0.130), And the results of the study showed that there are statistically significant differences in The results of the study showed that there were statistically significant differences (0.05) between males and females in the family compatibility mechanisms of young people used for social networks. The results of the study showed that there were statistically significant differences $(0.05)$ between males and females in the social compatibility of young people for social networks for females. The results of the study also showed that there are significant differences (0.05) between males and females in the social compatibility mechanisms of young people used for social networks for the benefit of females.

The study relied on two types of honesty: Apparent honesty: The researcher in the framework of the observance of the apparent honesty presented the questionnaire form to a number of professors arbitrators in order to evaluate and clarify the vision in the achievement of the tool for the purposes of research, the researcher benefited from the observations of arbitrators who have read the questionnaire, A survey of 20 subjects to ascertain the appropriateness of the questions, the modification of the questions that are not understood by the respondents and the legalization of the open questions. "A number of questions were added by the arbitrators, which are intrinsically related to the subject.

Stability: It is the stability of the responses in the case of repeated application of the tool in the sense of non-change in essence, and the same questionnaire was carried out on the vocabulary of the survey conducted ten days after the exploratory study was calculated

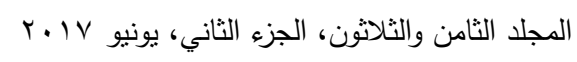


فاطمة بوسف القليني وآخرون

correlation coefficient between the responses in the tribal application and the 80,0 .

The study recommended that more awareness of the importance of social networks should be made through meetings and conferences.

The study recommended that the various educational curricula should contain parts of them to speak about the importance of social networks and warning against their dangers. It also recommended that the Ministries of Awqaf and Da'wa should be invited to the Arab countries in order to oblige the preachers to address people (the soft and beautiful) about the most important social misuse of social networks, and the need to enact laws and legislations that criminalize the bad use of social networks.

The need to address the media colleges and research centers spread throughout the Arab world about the need to encourage researchers and postgraduate students to conduct further research and studies on various social networks and their various impacts on the individual and society.

To encourage young people to devise Arab social networking networks, primarily aimed at serving Arab youth, with high financial rewards; to encourage young people to innovate.

$$
\text { المجلد الثامن والثلاثون، الجزء الثاني، يونيو Y Y r Y }
$$

